\title{
Rickettsia prowazekii Methionine Aminopeptidase as a Promising Target for the Development of Antibacterial Agents
}

Travis R. Helgrent, Congling Chent, Phumvadee Wangtrakuldeet, Thomas E. Edwards ${ }^{\ddagger}$, Bart L. Staker ${ }^{z, \Delta}$, Jan Abendroth ${ }^{\ddagger}$, Banumathi Sankaran`, Nicole A. Housley", Peter J. Myler ${ }^{z, \Delta, \bar{T}}$, Jonathon P. Audial, James R. Hornt, Timothy J. Hagent*

† Department of Chemistry and Biochemistry, Northern Illinois University, 1425 W. Lincoln Hwy, DeKalb, IL 60115, USA

‡ Beryllium LLC, 7869 NE Day Road West Bainbridge Island, WA 98110, USA

z Center for Infectious Disease Research, formerly Seattle Biomedical Research Institute, 307 Westlake Avenue N., Seattle, WA 98109, USA

$\Delta$ Seattle Structural Genomics Center for Infectious Disease (SSGCID), Seattle, WA, USA

T Department of Global Health and Department of Biomedical Informatics and Medical Education, University of Washington, Seattle, WA 98195, USA

- Berkeley Center for Structural Biology, Ernest Orlando Lawrence Berkeley National Laboratory, Berkeley, CA 94720, USA

|| Department of Microbiology and Immunology and The Center for Lung Biology, University of South Alabama College of Medicine, Laboratory of Infectious Diseases, 307 North University Blvd, Mobile, AL 36688, USA

KEYWORDS: MetAP, methionine aminopeptidase, inhibition, metalloenzyme, epidemic typhus, Rickettsia prowazekii, lung endothelial cells

\begin{abstract}
Methionine aminopeptidase (MetAP) is a class of ubiquitous enzymes essential for the survival of numerous bacterial species. These enzymes are responsible for the cleavage of $\mathrm{N}$-terminal formyl-methionine initiators from nascent proteins to initiate post-translational modifications that are often essential to proper protein function. Thus, inhibition of MetAP activity has been implicated as a novel antibacterial target. We tested this idea in the present study by targeting the MetAP enzyme in the obligate intracellular pathogen Rickettsia prowazekii. We first identified potent RpMetAP inhibitory species by employing an in vitro enzymatic activity assay. The molecular docking program AutoDock was then utilized to compare published crystal structures of inhibited MetAP species to docked poses of RpMetAP. Based on these in silico and in vitro screens, a subset of 23 compounds was tested for inhibition of $R$. prowazekii growth in a pulmonary vascular endothelial cell (EC) culture infection model system. All compounds were tested over concentration ranges that were determined to be non-toxic to the ECs and 10 of the 23 compounds displayed substantial inhibition of $R$. prowazekii growth. These data highlight the therapeutic potential for inhibiting RpMetAP as a novel antimicrobial strategy and set the stage for future studies in pre-clinical animal models of infection.
\end{abstract}




\section{Introduction}

Rickettsia prowazekii is an obligate intracytoplasmic pathogen and the causative agent of epidemic typhus fever in humans. ${ }^{1,2}$ Transmission of $R$. prowazekii is mediated by the human body louse and typically associates with deteriorated social conditions resulting in population crowding coupled with compromised sanitation and hygiene. ${ }^{3}$ These Gram-negative bacteria are vectored via growth in louse gut epithelium and R. prowazekii is highly stabile when shed in feces, which facilitates the potential for aerosol transmission. $R$. prowazekii is highly virulent, ${ }^{4,5}$ and populations with a low level of immunity are particularly susceptible to this disease. ${ }^{6}$ Patients with typhus exhibit signs and symptoms such as fever, malaise, myalgia, rash, and confusion that are common to numerous diseases, resulting in difficulty in establishing a timely diagnosis. ${ }^{7}$ R. prowazekii is designated a select agent pathogen and classified by the Center for Disease Control and Prevention (CDC) as a category B pathogen and potential bioterrorism agent. $^{8}$

Upon feeding on a human host, the $R$. prowazekii-infected louse defecates at the feeding site and host scratching results in sub-dermal inoculation. Post-inoculation, the rickettsiae ultimately enter the circulation and primarily infect vascular endothelial and immune cells. The rickettsiae attach to a host cell, induce phagocytosis, and rapidly escape the phagolysosome in a phospholipase $A_{2}$-dependent manner to grow free in the host cell cytoplasm. $R$. prowazekii typically grows to high numbers in the host cell cytoplasm and are released via host cell lysis to repeat the infection cycle ${ }^{2}$. The obligate intracellular nature of $R$. prowazekii significantly limits the repertoire of clinically effective antibiotic treatments to doxycycline, tetracycline and chloramphenicol. Considering the limited number of antibiotics available to treat rickettsioses and reports of $R$. prowazekii strains resistant to both tetracycline and chloramphenicol, ${ }^{9}$ the identification of novel targets for the development of antirickettsial therapeutics is needed. 
Nascent bacterial protein synthesis is initiated with an $\mathrm{N}$-terminal formyl-methionine residue that may be subsequently removed by the enzymatic activity of methionine aminopeptidases (MetAP) to facilitate proper protein function making this ubiquitous enzyme essential to many bacteria. ${ }^{10}$ Previous studies have implicated these enzymes as potentially useful targets for the discovery of novel antibiotics. For example, a nanomolar $\left(\mathrm{IC}_{50}\right)$ inhibitor of Burkholderia pseudomallei MetAP1 was found to exhibit growth inhibition of $B$. thailandensis. ${ }^{11}$ In the present study, the inhibition activities of three distinct chemical classes of compounds (furoic acids, 1,2,4-triazoles and quinolinols) were evaluated against $R$. prowazekii MetAP1. Structure-activity relationship (SAR) analyses, along with molecular docking, were used to explore potential interactions of these inhibitors within the RpMetAP active site. Finally a subset of 23 inhibitors identified in these in silico and in vitro screens were tested for inhibition of $R$. prowazekii growth in a cell culture model infection system.

\section{Results and Discussion}

\subsection{Crystal Structures of RpMetAp}

The crystal structure of $R$. prowazekii MetAP was solved in two different crystal forms, to $1.7 \AA$ and $2.0 \AA$ resolution. Seven different constructs were designed using structure-based alignments to Escherichia coli MetAP (EcMetAP). Constructs varied by small truncations at both the $\mathrm{N}$ and $\mathrm{C}$ terminus of the RpMetAP sequence of 259 residues (see Supplemental Information, Table S2) as well as 2 fulllength constructs with different $\mathrm{N}$-terminal His-tagged extensions, where $\mathrm{A}$ and $\mathrm{B}$ refer to cleavable and non-cleavable His-tag constructs, respectively. These seven constructs were processed through the Seattle Structural Genomics Center for Infectious Disease (SSGCID) high throughput protein production pipeline concurrently. Constructs A1(1-259), A2(1-247), and A3(1-249) expressed insoluble protein. Constructs B1(1-259), A4(3-259), and A6(3-249) expressed soluble protein, were purified and subjected 
to crystallization trials. Construct A5(3-247) failed at initial cloning, likely due to technical reasons, and was not pursued further. Given that an N-terminal methionine is added to each sequence during cloning, the only difference between the amino termini of the sequences $A 1(1-259)$ and $A 4(3-259)$ as well as $A 3(1-249)$ and $A 6(3-249)$ is a single threonine residue at position 2 in the wild type sequence. This deletion of one residue led to the production of soluble protein in the A4 and A6 constructs, as compared to the insoluble $\mathrm{A} 1$ and $\mathrm{A} 3$ constructs.

Constructs A4(residues 3-259) and A6(residues 3-249) both crystallized and diffracted X-rays to high resolution. The structure of construct A4(3-259) bound to methionine and the apo structure of construct A6(3-249) were refined to $1.7 \AA$ and $2.0 \AA$, respectively, and deposited into the Protein Data Bank (PDB) as 3MX6 and 3MR1. The A4 structure contained two copies of the protein in the asymmetric unit and the $A 6$ construct contained four copies of the protein in the asymmetric unit. The two crystal structures are highly similar with an average root mean squared difference (r.m.s.d.) of only $0.34 \AA$ for $\mathrm{C}_{\alpha}$ atoms. The $\mathrm{C}$-terminal portions of both the $\mathrm{A} 4$ and $\mathrm{A} 6$ proteins are present in both crystal structures with A4 being ordered through residue Tyr259 and the A6 construct being ordered through Leu249; we note that the numbering scheme used for the crystal structures does not include the $\mathrm{N}$-terminal methionine and thus the above residues are labeled Tyr258 and Leu248.

The overall structural fold of RpMetAP was highly similar to MetAP enzymes from other species ranging from bacteria to human. The root mean squared difference (r.m.s.d.) of the core 250 residue 'pita bread' fold between the R. prowazekii MetAP as compared to Pseudomonas aeruginosa (PDB: 4FO7), E. coli (PDB: $1 \mathrm{XNZ}^{12}$ ) and Homo sapiens (PDB: $4 \mathrm{U}^{1} \mathrm{~B}^{13}$ ) was $0.985 \AA$, $0.711 \AA$, and $0.865 \AA$, respectively. For both the $\mathrm{A} 4$ and $\mathrm{A} 6 \mathrm{RpMetAP}$ structures, no divalent metal ion was included in the crystallization conditions. Two metal ions were clearly present in the electron density. These features were modeled as $\mathrm{Mn}$ (II) ions based off similar structures in the literature as well as proper refinement with $B$-factors similar to those of surrounding protein atoms, octahedral geometry and mean bond 
distances of 2.1-2.2 $\AA$ which are appropriate for $\mathrm{Mn}(\mathrm{II}) .{ }^{14}$ The CheckMyMetal server ${ }^{15}$ was largely in agreement on metal ion selection, although it suggested copper or cobalt as possible alternatives; however, neither of these metal ions refined with $B$-factors equivalent to those of the surrounding residues. For the A4 structure, an additional electron density feature was present, which modeled well as methionine, a byproduct of the enzymatic activity (PDB: 3MX6, Figure 1). In contrast, the A6 construct crystallized in the presence of phosphate buffer, and a phosphate appears bound to both metal ions; the phosphate ion overlays well with the carboxylate of the bound methionine residue. This phosphate orientation is likely biologically relevant (i.e. reflects the binding mode observed for methionine, Figure 1B) since the enzymatic reaction would proceed through a sp3 hybridized transition state and similar interactions with His78, His176, and Glu202 (His77, His175 and Glu201, respectively in Figure 1) would be expected.
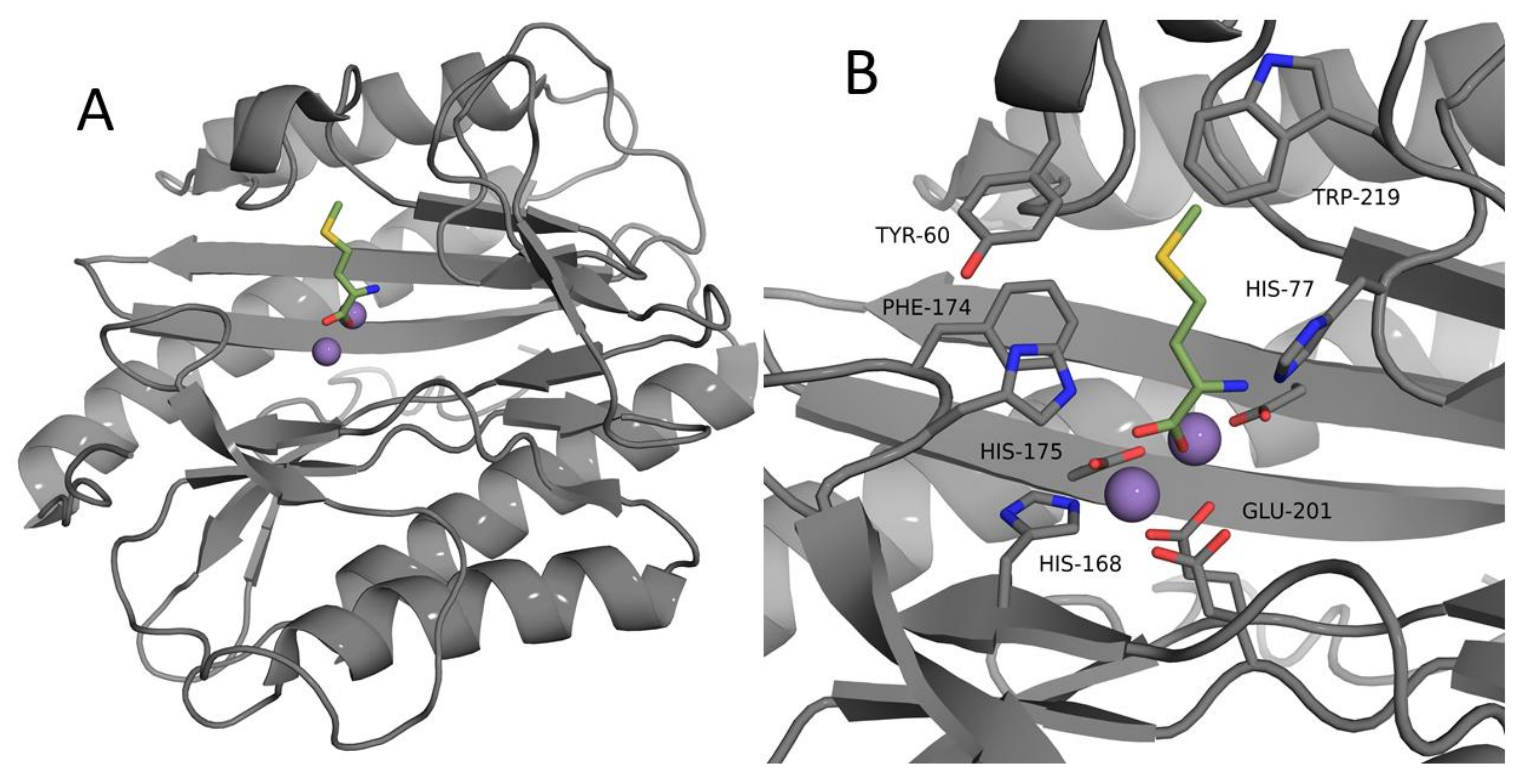

Figure 1: RpMetAP1 (PDB: 3MX6) with bound methionine. A: RpMetAP represented as a cartoon. B: Zoom-in of the RpMetAP active site. Purple spheres designate $\mathrm{Mn}(\mathrm{II})$ cofactors and the green residue is the bound methionine. 


\subsection{Compound Syntheses}

Various classes of inhibitors have been determined to inhibit MetAP activity, including furoic acids, 1,2,4-traizoles, and quinolinols; compounds of these scaffolds were therefore utilized for our study. ${ }^{16}$ It is noteworthy that some compounds based upon the quinolinol scaffold have been identified as pan-assay interference compounds (PAINS) ${ }^{17}$ due to both their promiscuous inhibition of metalloenzymes and their ability to form reactive methides. As this is early stage, proof of concept research, this information can useful in the design of next generation compounds that are devoid of such characteristics. Importantly, this subset of compounds (24-26) do exhibit selective toxicity towards R. prowazekii growing within mammalian host cells (see below) and we have therefore included a discussion of their observed activity and SAR.

Regarding our routes to obtain a screening test set, compounds $(\mathbf{1}-\mathbf{1 1})$ bearing the furoic acid scaffolding were purchased from a commercial source (Sigma Aldrich, St. Louis, MO). The synthesis of the triazole species was previously reported ${ }^{11}$ (Scheme 1). Briefly, the compounds were synthesized by base promoted addition of substituted benzyl bromides to the 5-amino-4H-1,2,4-triazole-3-thiol starting material. The reactions were carried out under aqueous conditions and afforded product in fair yield (47 -92\%). Regarding the synthesis of oxine Mannich derivatives, the starting materials were suspended in EtOH and heated overnight to afford the desired products in good yield (43-95\%) (Scheme 2). ${ }^{11}$ 


\section{Scheme 1}

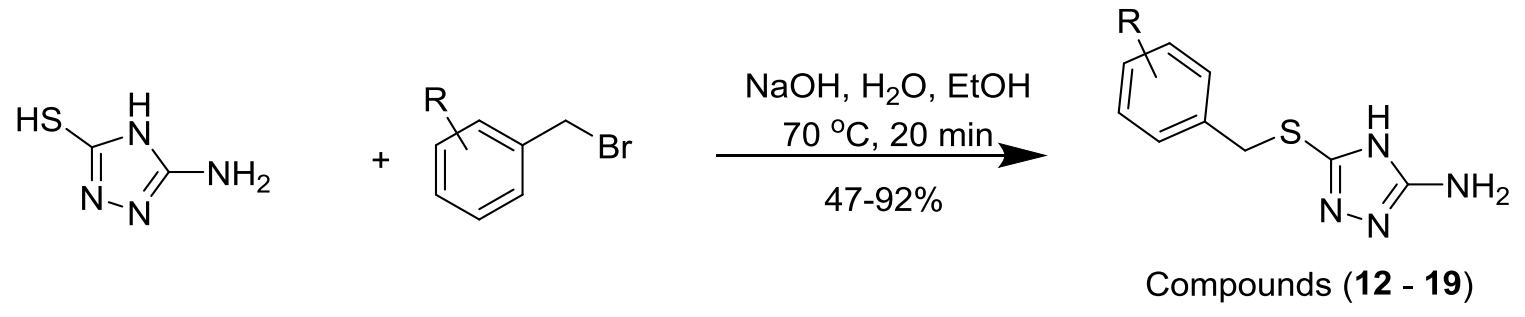

\section{Scheme 2}<smiles>[X]c1ccc(O)c2ncccc12</smiles>
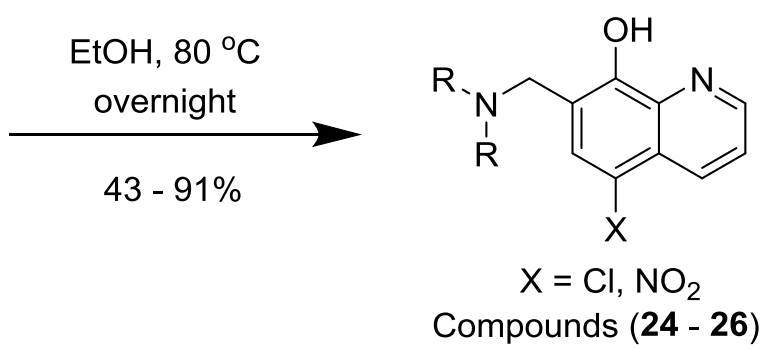

\subsection{Enzymatic Activity Assay}

\subsubsection{Assay Procedure}

Following the synthesis of compounds designed to evaluate the SAR of published bacterial MetAP inhibitors, an enzymatic activity assay was used to evaluate inhibition potencies. The assay employed was adopted from published reports, ${ }^{11,18}$ where MetAP activity is monitored as a function of product formation. Utilizing methionyl aminomethylcoumarin (Met-AMC) as the substrate, enzymatic turnover will cleave the peptide bond producing free AMC, a fluorescent compound with emission at $460 \mathrm{~nm}$. 


\subsubsection{Activity of Furoic Acid Derivatives}<smiles></smiles>

Table 1: Activity of furoic acid species against RpMetAP1

\begin{tabular}{cccccccc}
\hline Compound & $\mathbf{X}$ & $\mathbf{R} 1$ & $\mathbf{R 2}$ & $\mathbf{R 3}$ & $\mathbf{R 4}$ & IC $_{\mathbf{5 0}}(\boldsymbol{\mu M})$ & Hill Slope \\
\hline $\mathbf{( 1 )}$ & $\mathrm{S}$ & $\mathrm{H}$ & $\mathrm{H}$ & $\mathrm{H}$ & $\mathrm{H}$ & $74 \pm 7$ & $1.2 \pm 0.2$ \\
$\mathbf{( 2 )}$ & $\mathrm{O}$ & $\mathrm{H}$ & $\mathrm{NO}_{2}$ & $\mathrm{H}$ & $\mathrm{H}$ & $77 \pm 4$ & $1.0 \pm 0.1$ \\
$\mathbf{( 3 )}$ & $\mathrm{O}$ & $\mathrm{H}$ & $\mathrm{CF}_{3}$ & $\mathrm{H}$ & $\mathrm{H}$ & $46 \pm 2$ & $1.0 \pm 0.1$ \\
$\mathbf{( 4 )}$ & $\mathrm{O}$ & $\mathrm{H}$ & $\mathrm{H}$ & $\mathrm{H}$ & $\mathrm{H}$ & $37 \pm 3$ & $1.0 \pm 0.1$ \\
$\mathbf{( 5 )}$ & $\mathrm{O}$ & $\mathrm{H}$ & $\mathrm{H}$ & $\mathrm{Me}$ & $\mathrm{H}$ & $57 \pm 2$ & $1.0 \pm 0.1$ \\
$(\mathbf{6 )}$ & $\mathrm{O}$ & $\mathrm{CF}_{3}$ & $\mathrm{H}$ & $\mathrm{H}$ & $\mathrm{H}$ & $0.5 \pm 0.1$ & $2.1 \pm 0.1$ \\
$(\mathbf{7})$ & $\mathrm{O}$ & $\mathrm{H}$ & $\mathrm{H}$ & $\mathrm{Br}$ & $\mathrm{H}$ & $60 \pm 5$ & $1.0 \pm 0.1$ \\
$(\mathbf{8})$ & $\mathrm{O}$ & $\mathrm{Me}$ & $\mathrm{H}$ & $\mathrm{H}$ & $\mathrm{H}$ & $0.9 \pm 0.1$ & $1.3 \pm 0.1$ \\
$(\mathbf{9})$ & $\mathrm{O}$ & $\mathrm{H}$ & $\mathrm{Me}$ & $\mathrm{H}$ & $\mathrm{H}$ & $26 \pm 1$ & $1.0 \pm 0.1$ \\
$(\mathbf{1 0})$ & $\mathrm{O}$ & $\mathrm{Cl}$ & $\mathrm{H}$ & $\mathrm{H}$ & $\mathrm{H}$ & $0.6 \pm 0.1$ & $1.2 \pm 0.1$ \\
$(\mathbf{1 1})$ & $\mathrm{O}$ & $\mathrm{Cl}$ & $\mathrm{H}$ & $\mathrm{H}$ & $\mathrm{Cl}$ & $0.6 \pm 0.1$ & $0.6 \pm 0.1$ \\
\hline
\end{tabular}

Furoic acid based inhibitors of bacterial MetAPs are among the most potent reported in the current literature. ${ }^{16}$ Species of this general structure only exhibit potent inhibition of MetAPs containing $\mathrm{Mn}(\mathrm{II})$ cofactors, with essentially no activity observed for MetAPs possessing $\mathrm{Fe}(\mathrm{II}), \mathrm{Co}(\mathrm{II})$ or $\mathrm{Ni}(\mathrm{II})$ metals. ${ }^{16}$ Although this class of inhibitors have demonstrated activity against a number of bacterial MetAPs, including Mycobacterium tuberculosis, ${ }^{18-19}$ B. pseudomallei, ${ }^{11}$ E. coli. $^{12,20}$ and Acinetobacter baumannii, ${ }^{21}$ there are currently no reports detailing the selectivity of bacterial versus human MetAPs.

Published reports detailing the inhibition of bacterial MetAPs by furoic acids and thiophenic acids $^{11-12,18-21}$ have suggested the most potent compounds contain small substituents at the ortho $\left(\mathrm{R}_{1}\right)$ position. Generally, the compounds bind via bidentate coordination through the carboxylate to one of the active site metals, with one of the oxygen atoms also exhibiting coordination to the other cofactor 
(PDB: 3MAT). ${ }^{12}$ This binding mode results in a competitive mechanism of inhibition where the catalytic site is blocked by inhibitor coordination, effectively eliminating access by substrate.

In the present study, compound (6) utilizes a trifluoromethyl substituent at the ortho $\left(R_{1}\right)$ position and was observed to be the most active compound of this chemical series $\left(\mathrm{IC}_{50}=0.5 \mu \mathrm{M}\right)(\mathrm{Table}$ 1). Such activity was essentially mirrored by other compounds utilizing substitution at $R_{1}$, namely (8), (10) and (11), with inhibitory values of $0.9,0.6$, and $0.6 \mu \mathrm{M}$, respectively. Only one species containing meta $\left(\mathrm{R}_{2}\right)$ substitution, 3-methyl derivative (9), exhibited greater activity to that of unsubstituted 5phenyl-2-furoic acid (4), with inhibitory values of 26 and $37 \mu \mathrm{M}$, respectively. All other 3 and 4 substituted aryl furoic acids were found to only weakly inhibit enzymatic activity. As with other reports, ${ }^{20 \mathrm{~d}} 5$-phenyl-2-thiophenic acid (1) was found to exhibit weaker activity than that of the corresponding furan (IC $\mathrm{C}_{50}=74$ and $37 \mu \mathrm{M}$, respectively). It is noteworthy that compound (6) exhibited the only Hill slope outlier $(2.1 \pm 0.1)$ and also exhibited the most potent inhibitory activity. As the enzyme concentration was fixed at $1 \mu \mathrm{M}$, this may reflect the minimum inhibitory concentration detectable by this assay. 


\subsubsection{Activity of Triazole Derivatives}<smiles>[R]c1ccc(CSc2nnc(N)[nH]2)c([R])c1</smiles>

Table 2: Activity of triazole species against RpMetAP1

\begin{tabular}{ccccc}
\hline Compound & $\mathbf{R}_{\mathbf{1}}$ & $\mathbf{R}_{\mathbf{2}}$ & $\mathbf{I C}_{\mathbf{5 0}}(\boldsymbol{\mu M})$ & Hill Slope \\
\hline $\mathbf{( 1 2 )}$ & $\mathrm{H}$ & $\mathrm{H}$ & $6.6 \pm 1.0$ & $1.1 \pm 0.2$ \\
$\mathbf{( 1 3 )}$ & $\mathrm{H}$ & $\mathrm{Me}$ & $23 \pm 3$ & $0.9 \pm 0.1$ \\
$(\mathbf{1 4})$ & $\mathrm{H}$ & $\mathrm{F}$ & $28 \pm 6$ & $1.0 \pm 0.2$ \\
$(\mathbf{1 5 )}$ & $\mathrm{Cl}$ & $\mathrm{H}$ & $15 \pm 2$ & $1.2 \pm 0.1$ \\
$(\mathbf{1 6})$ & $\mathrm{H}$ & $\mathrm{Cl}$ & $30 \pm 2$ & $1.6 \pm 0.6$ \\
$(\mathbf{1 7})$ & $\mathrm{Cl}$ & $\mathrm{Cl}$ & $7.7 \pm 0.9$ & $1.3 \pm 0.3$ \\
$(\mathbf{1 8})$ & $\mathrm{H}$ & $i \mathrm{Pr}$ & $14 \pm 1$ & $0.6 \pm 0.2$ \\
$(\mathbf{1 9 )}$ & $\mathrm{H}$ & $t \mathrm{Bu}$ & $14 \pm 1$ & $1.5 \pm 0.4$ \\
\hline
\end{tabular}

Species bearing the 1,2,4-triazole scaffold have been shown to inhibit MetAPs from both bacterial $^{11,18-19,21-22}$ and human ${ }^{23}$ sources. These compounds have been shown to most effectively inhibit MetAPs utilizing $\mathrm{Co}(\mathrm{II})$ or $\mathrm{Ni}(\mathrm{II})$ cofactors in vitro, with weaker activity observed for $\mathrm{Mn}$ (II) cofactors. ${ }^{16}$ Interestingly, MetAP species bearing Fe(II) cofactors exhibit essentially no reduction in enzymatic turnover in the presence of triazole inhibitors.

Crystal structures detailing the binding of 1,2,4-triazoles to bacterial MetAP targets exist (PDB: $3 I U 8,3(\cup 9),{ }^{19}$ where compounds bind via coordination of the $1 \mathrm{~N}$ and $2 \mathrm{~N}$ atoms of the triazole ring to the divalent metal cofactors embedded within the active site of MetAPs. Additional binding contacts generally include $\pi-\pi$ stacking with aromatic residues (phenylalanine, histidine, and tyrosine) occupying adjacent space to the substrate-binding pocket. A similar binding mechanism is observed for HsMetAP2, with coordination to the metal cofactors by the triazole ring and additional $\pi-\pi$ stacking to aromatic residues (PDB: 2OAZ). ${ }^{23}$ 
Concerning the inhibition of RpMetAP by 1,2,4-triazoles, we determined the most potent compounds utilize electron withdrawing groups $\left(\mathrm{Cl}\right.$ or $\mathrm{F}$ ) at the $\mathrm{R}_{1}$ and $\mathrm{R}_{2}$ position; other reports detailing the inhibition of bacterial MetAPs by this chemical class have confirmed this observation (Table 2). ${ }^{18,21}$ However, the most potent compound containing benzyl thioethers employed in our study was found to be unsubstituted derivative (12) with an $\mathrm{IC}_{50}$ value of $6.6 \mu \mathrm{M}$, although 2,4-dichloro derivative (15) exhibited comparable activity $\left(\mathrm{IC}_{50}=7.7 \mu \mathrm{M}\right)$.

\subsubsection{Activity of Quinolinol Derivatives}<smiles>[R]c1ccc2c([R])cc([R])c(O)c2n1</smiles>

Table 3: Activity of quinolinol species against RpMetAP1

\begin{tabular}{|c|c|c|c|c|c|}
\hline Compound & $R_{1}$ & $\mathbf{R}_{\mathbf{2}}$ & $\mathbf{R}_{\mathbf{3}}$ & $I C_{50}(\mu \mathrm{M})$ & Hill Slope \\
\hline (20) & $\mathrm{CH}_{3}$ & $\mathrm{H}$ & $\mathrm{H}$ & $1.4 \pm 0.1$ & $1.1 \pm 0.1$ \\
\hline (21) & $\mathrm{H}$ & $\mathrm{H}$ & $\mathrm{H}$ & $1.0 \pm 0.3$ & $1.2 \pm 0.1$ \\
\hline$(22)$ & $\mathrm{H}$ & $\mathrm{Cl}$ & $\mathrm{H}$ & $0.9 \pm 0.1$ & $1.9 \pm 0.2$ \\
\hline (23) & $\mathrm{H}$ & $\mathrm{NO}_{2}$ & $\mathrm{H}$ & $1.3 \pm 0.7$ & $1.7 \pm 0.5$ \\
\hline (24) & $\mathrm{H}$ & $\mathrm{Cl}$ & & $2.5 \pm 0.1$ & $1.5 \pm 0.1$ \\
\hline (25) & $\mathrm{H}$ & $\mathrm{NO}_{2}$ & & $73 \pm 38$ & $1.2 \pm 0.4$ \\
\hline (26) & $\mathrm{H}$ & $\mathrm{NO}_{2}$ & & $16 \pm 4$ & $1.0 \pm 0.1$ \\
\hline
\end{tabular}

Compounds composed of the 8-quinolinol scaffold have been screened against MetAPs from $B$. pseudomallei, ${ }^{11}$ M. tuberculosis, ${ }^{24}$ E. coli, ${ }^{25}$ Staphylococcus aureus, ${ }^{25 c}$ and against those of human origin. ${ }^{25 c}$ The chelating ability of 8-quinolinol derivatives affords an interesting mechanism of binding for metalloenzymes as demonstrated by the crystal structure of an 8-quinolinol derivative bound to $E$. coli 
MetAP (PDB: 2BB7), ${ }^{25 b}$ although the inhibitor is the related compound, 8-quinolinyl-

methanesulfonamide. The crystal structure shows the inhibitor binding to a tertiary $\mathrm{Mn}$ (II) cofactor found within the active site, and the inhibitor potency was found to be dependent upon the

concentration of $\mathrm{MnCl}_{2}$ added to the assay buffer. ${ }^{25 \mathrm{~b}}$ Given the structure-activity relationship previously discovered for the inhibition of $B$. pseudomallei, ${ }^{11}$ we felt it was appropriate to screen a class of aminoalkylated quinolinol analogues against $R$. prowazekii MetAP.

In our previous study investigating the inhibition of $B p M e t A P 1,{ }^{11}$ it was found that quinolinol derivatives utilizing $\mathrm{NO}_{2}$ groups para $\left(\mathrm{R}_{2}\right)$ to the hydroxyl group exhibited the most potent activity. Species bearing $\mathrm{Cl}$ groups at the same position were essentially inactive. In this study, the opposite appears to be true, with all $\mathrm{Cl}$ derivatives being more potent inhibitors than the corresponding $\mathrm{NO}_{2}$ derivatives. However, the metals employed as cofactors for this study were $\mathrm{Mn}$ (II), while Co(II) was used previously in the study of $B$. pseudomallei MetAP inhibitors. This may explain the observed difference in activity regarding $\mathrm{Cl}$ or $\mathrm{NO}_{2}$ substitution, as observed activities have been documented to be highly dependent upon the identity of the metallic cofactors. ${ }^{25 b}$

When compared to aminoalkylated derivatives, unsubstituted quinolinols exhibited superior activity. For example, the most active species was found to be 5-chloro-8-quinolinol (22), with an IC 50 value of $0.9 \mu \mathrm{M}$. All other derivatives (2-methyl-8-quinolinol (20), 8-quinolinol (21), and nitroxoline (23)) exhibited comparable activity to that of (22). Concerning aminoalkylated derivatives, all were inferior inhibitors than the corresponding quinolinol fragments.

\subsection{Molecular Docking}

To discern potential binding interactions and to aid in the development of new MetAP inhibitors, test compounds from each class were docked into the crystal structure of $R$. prowazekii 
MetAP1 (PDB: 3MX6) and the docking poses and scores were compared to the observed inhibitory data and currently available crystal structures. The docking studies were performed using the open-source program AutoDock. ${ }^{26}$ The numerous crystal structures of E. coli MetAP including substituted 5-aryl-2furoic acids (PDB: $1 \mathrm{XNZ},{ }^{12} 2 \mathrm{EVM},{ }^{20 \mathrm{e}} 2 \mathrm{Q} 92,{ }^{27} 2 \mathrm{Q} 93,{ }^{27} 2 \mathrm{Q} 94,{ }^{27} 2 \mathrm{Q} 95,{ }^{27} 2 \mathrm{Q} 96,{ }^{27}$ and $3 \mathrm{IU} 7^{19}$ ) served as models to validate the docking output from AutoDock (see Supplemental Information). A sequence alignment was performed to discern the conservation between EcMetAP1 and RpMetAP1 (PDB: 1 XNZ ${ }^{12}$ and $3 \mathrm{MX6}$ ), which are 53\% identical (Figure 2). Based upon the three-dimensional structure, the active site, including the five residues responsible for metal cofactor binding and residues composing the active site surface, is highly conserved.

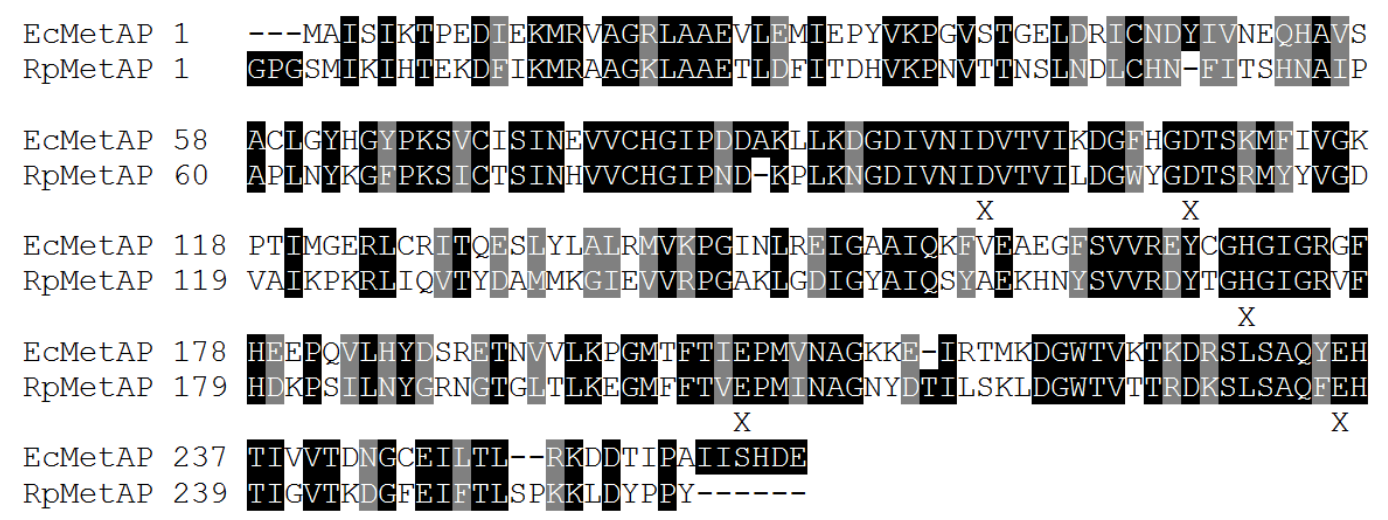

Figure 2: Sequence alignment of EcMetAP1 (PDB: 1XNZ) ${ }^{12}$ and RpMetAP1 (PDB: 3MX6) shaded according to alignment (dark = identity; light = similarity; no shading = non-conserved). Alignment reveals 53\% identity between the proteins. Residues involved in cofactor binding are marked as $X$

The crystal structure of the EcMetAP/furoic acid (10) complex reveals contacts responsible for potent inhibition (Figure 3B). The most important interactions between the ligand and receptor involve coordination to both the metal cofactors via the carboxylate, $\pi-\pi$ interactions with Tyr62 and hydrophobic interactions with His63, Tyr65, His79, Phe177, His178 and Trp221 (Table 4). Additionally, 
the furoic acid inhibitor exhibits a dihedral angle of $40.6^{\circ}$ between the furan and aryl ring. As previously stated, this rotated bi-aryl ring system is necessary for potent inhibition, maximizing interactions with Tyr62. Thus, the incorporation of large substituents at the ortho position affords hindered rotation about the bi-aryl axis, resulting in an increase in the dihedral angle, which serves as the basis for the observed increase in activity for this substitution pattern.

Table 4: Comparison of binding interactions for (10) in crystal and docked structures

\begin{tabular}{ccc}
\hline Distance $^{\mathrm{a}, \mathrm{b}}$ & EcMetAP1 Actual & RpMetAP1 Docked \\
\hline Mn(II) Chelation & $2.2,2.3$ & $1.7,2.1$ \\
Mn(II) Coordination & 2.0 & 1.8 \\
$\pi-\pi$ Stacking (Tyr62) & 4.0 & 3.1 \\
Hydrophobic (His63) & 3.5 & $6.9^{\mathrm{c}}$ \\
Hydrophobic (Tyr65) & 3.6 & 3.5 \\
Hydrophobic (His79) & 3.6 & 3.9 \\
Hydrophobic (Phe177) & 4.0 & 3.3 \\
Hydrophobic (His178) & 3.3 & 3.6 \\
Hydrophobic (Trp221) & 3.4 & 3.1 \\
& & $155^{\circ}$ \\
\hline Angle & $107^{\circ}$ & $18^{\circ}$ \\
\hline & $41^{\circ}$ & \\
Mn(II) - O - Mn(II) Angle & & \\
(10) Dihedral & & \\
\hline a. Distances correspond to closest observed interaction and are reported in $\AA$ \\
b. Residue numbering corresponds to EcMetAP1 (PDB: 1XNZ) \\
C. This is a non-conserved residue and exists as Lys in RpMetAP \\
\hline
\end{tabular}

The series of furoic acid inhibitors (Table 4) was screened in silico against RpMetAP1 to optimize the docking method. Because AutoDock does not automatically assign charges to metal ions, the charge of the $\mathrm{Mn}(\mathrm{II})$ cofactors found within the RpMetAP1 structure (3MX6) was manually set at 0.5 elementary charge units (see Supplemental Information). Additionally, compound (10) was previously crystallized with EcMetAP1 as a bound structure (1XNZ), ${ }^{12}$ allowing for the comparison of the predicted docking pose and crystal structures for two highly conserved MetAPs of bacterial origin. 
The highest scored docking pose of (10) reveals a binding mode similar to that observed in the crystal structure of (10) bound to EcMetAP1 (Figure 3). As demonstrated in Table 4, the differences in protein-ligand interactions between the crystal and docked structures ranged from $0.1-0.9 \AA$. However, the most obvious difference between the docked and crystal structures is the dihedral angle between the ring systems of the furoic acid inhibitor. The dihedral angle for the docked structure was significantly reduced, at $18^{\circ}$, compared to that of the actual pose (see Supplemental Information). Examination of the $\mathrm{Mn}-\mathrm{O}-\mathrm{Mn}$ bond angle and $\mathrm{Mn}-\mathrm{O}$ bond distances demonstrates the closer spatial orientation of the inhibitor in the docked pose as compared to that of the actual crystal structure. The large $\mathrm{Mn}-\mathrm{O}-\mathrm{Mn}$ bond angle $\left(155^{\circ}\right)$ and shortening of the chelation distance between the $\mathrm{Mn}$ and carboxylate for the docked pose revealed stronger predicted interactions than actually observed (Table 4). The chloride substituent was also found to point into the middle of the substrate binding pocket, rather than coordinate to residues lining the active site as seen in the crystal structure. 


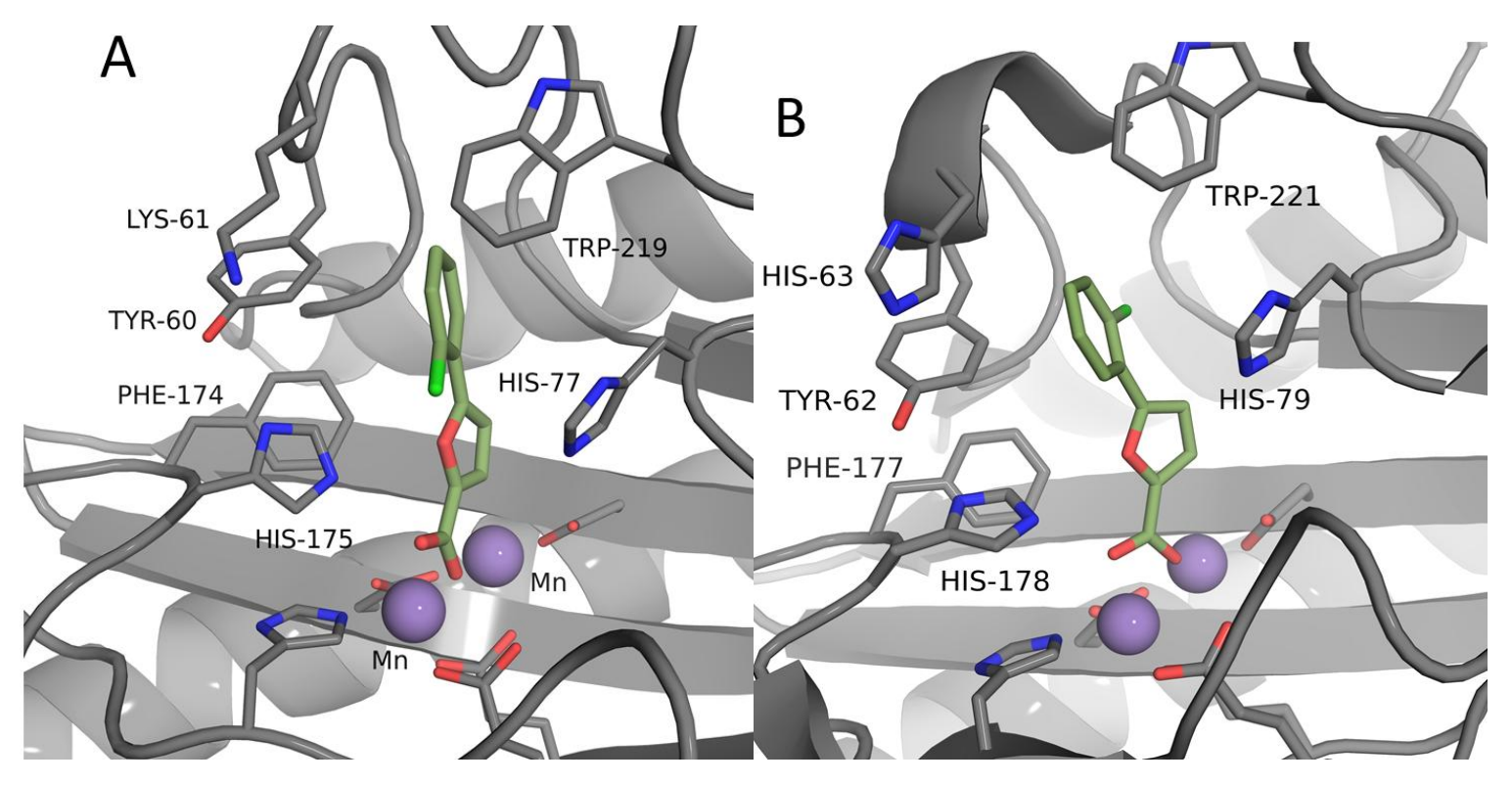

Figure 3: Comparison of docked and observed binding interactions of (10). A: Docked pose of (10) with RpMetAP (PDB: 3MX6). B: Crystal structure of (10) bound to EcMetAP (PDB: 1XNZ). ${ }^{12}$ Note that residue numbering differs by two between the two MetAP species (Ex: RpMetAP Tyr60 and EcMetAP Tyr62 are equivalent).

\subsection{Comparison of HsMetAPs and RpMetAP1}

To develop selective inhibitors that target bacterial MetAPs, a detailed understanding of the differences between bacterial and human MetAP structures is necessary. The sequence alignment of RpMetAP1 and HsMetAP1 indicates the enzymes are 43\% identical, with all 5 residues responsible for cofactor binding being conserved (Figure 4, bottom). Active site residues were found to be highly conserved, with only a few significant non-conserved residues lining the entrance to the binding pocket (Lys61Tyr, Asp164Ser, Thr166Cys, Ser179Asn, and Leu213Thr, indicating the residue change from Hs to $R p)$ as demonstrated by the colored surface model shown in Figure 4. Selective inhibitors will likely utilize binding to the metal cofactors as an anchor for proper binding orientation while targeting interactions with the non-conserved residues. The closest non-conserved residue near the active site of RpMetAP1 is Lys61. Inhibitors have been found to interact with this residue position for EcMetAP1 ${ }^{12}$ 
(histidine for the E. coli isoform (His63), see Figure 3) and selective inhibition of RpMetAP1 may result from designing inhibitors targeting Lys61. Although docking studies of (10) with RpMetAP1 suggests Lys61 lies too far from the active site to allow favorable interactions with bound inhibitors (Table 4), new molecular species could be designed to capitalize upon this lack of conservation and yield selective inhibition.

Of the species screened for RpMetAP1 inhibitory activity $(\mathbf{1}-\mathbf{2 6})$, compounds bearing the quinolinol scaffold have been evaluated against both HsMetAP1 and HsMetAP2, previously. ${ }^{28}$ Because HsMetAP1 was determined to be most active with Co(II) cofactors, this metal was employed in the screening of quinolinol compounds in the published report. ${ }^{28}$ Additionally, $\mathrm{Mn}(\mathrm{II})$ has been suggested as the native cofactor for HsMetAp2 and this metal was used in the corresponding assays. ${ }^{28-29}$ In the present study, the compounds exhibit selective inhibition of RpMetAP1 over HsMetAp1, with the compounds generally being inactive against HsMetAp1 (Table 5). This result is interesting, as quinolinol species have been demonstrated to inhibit MetAP species utilizing Co(II) cofactors over species utilizing $\mathrm{Mn}(\mathrm{II})$ cofactors. ${ }^{16}$ The quinolinol compounds were not as selective against HsMetAP2, with the observed activities being comparable to RpMetAP1 (Table 5). However, HsMetAP2 inhibition has been suggested as a treatment for tumor growth abatement (antiangiogenic properties) ${ }^{30}$ and a lack of specificity regarding these two targets may not be of striking clinical significance. 

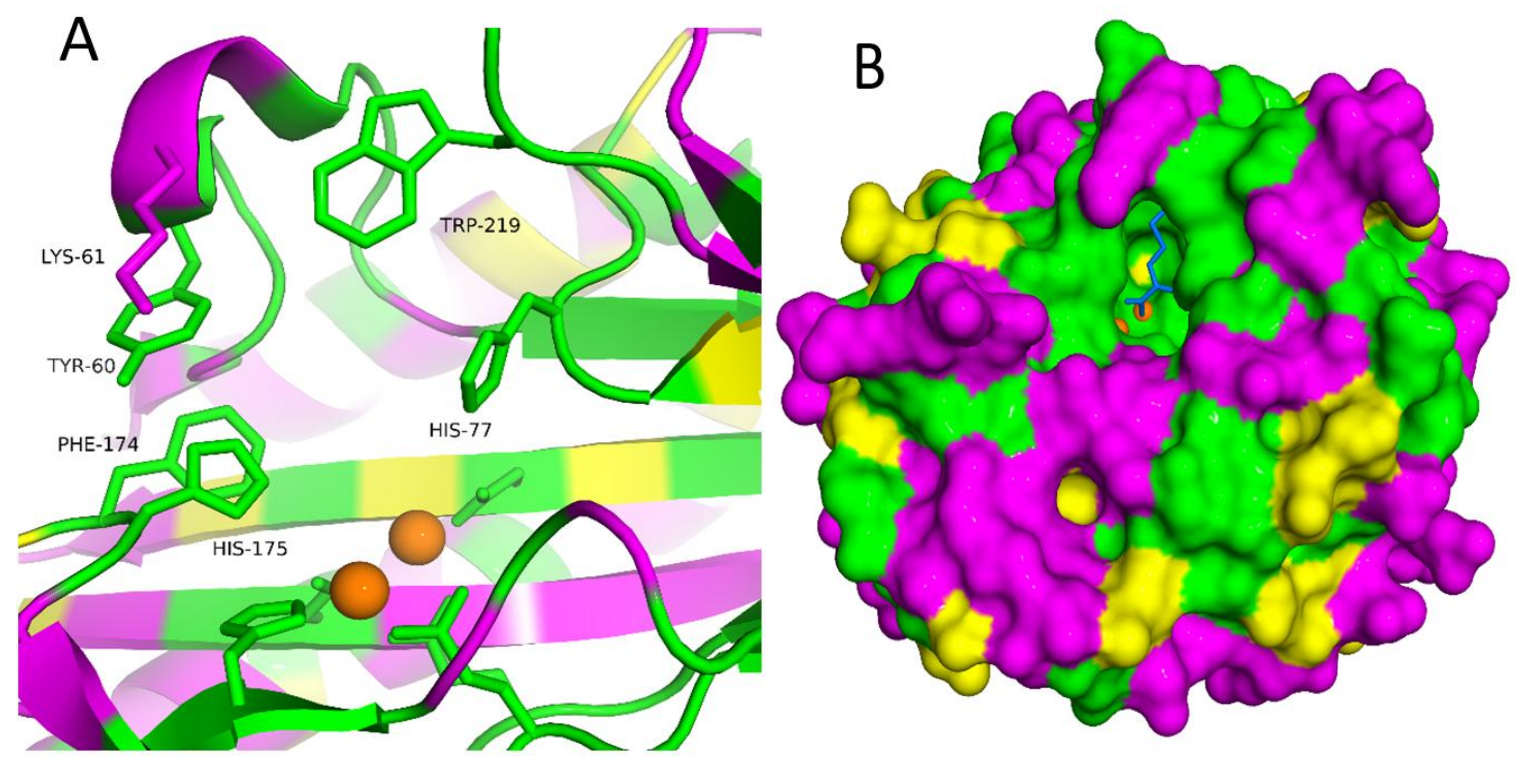

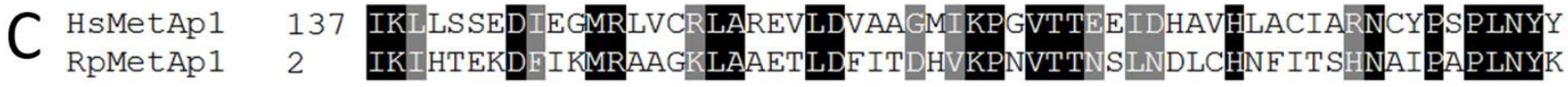

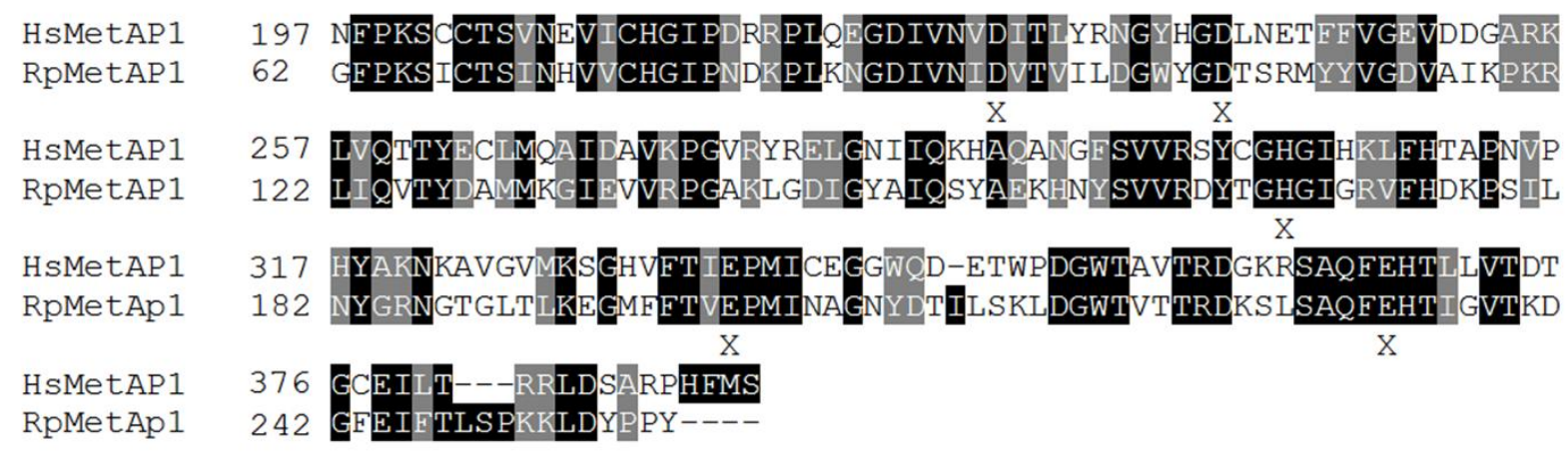

Figure 4: Comparison of HsMetAP1 and RpMetAP1 sequences. A: Active site of RpMetAP1 colored according to sequence alignment (green = identity; yellow = similarity; magenta = non-conserved). $\mathbf{B}$ : Surface diagram of RpMetAp1 colored according to sequence alignment (green = identity; yellow = similarity; magenta = non-conserved). The blue ligand is a bound methionine and orange spheres are manganese cofactors. C: Sequence alignment of RpMetAP1(PDB: 3MX6) and HsMetAP1 (PDB: 2B3K) shaded according to alignment (dark = identity; light = similarity; no-shading = non-conserved). Alignment reveals $43 \%$ identity between the proteins. Residues responsible for cofactor binding are marked as $\mathrm{X}$. 
Table 5: Comparison of activity $\left(\mathrm{IC}_{50}\right)$ against RpMetAP and HsMetAPs

\begin{tabular}{|c|c|c|c|}
\hline Compound & RpMetAP1 ${ }^{\mathrm{a}, \mathrm{b}}$ & HsMetAP1 ${ }^{\mathrm{c}, \mathrm{d}}$ & HsMetAP2 $2^{\mathrm{c}, \mathrm{e}}$ \\
\hline$(19)$ & $1.4 \pm 0.1$ & $>15$ & $>15$ \\
\hline (20) & $1.0 \pm 0.3$ & $>15$ & $2.03 \pm 0.3$ \\
\hline (21) & $0.9 \pm 0.1$ & $12.9 \pm 1.0$ & $1.27 \pm 0.6$ \\
\hline (22) & $1.3 \pm 0.7$ & $>15$ & $0.055 \pm 0.02$ \\
\hline \multicolumn{4}{|c|}{ a. $I C_{50}$ values in $\mu \mathrm{M}$} \\
\hline \multicolumn{4}{|c|}{$\begin{array}{l}\text { b. IC } C_{50} \text { values and standard error obtained from nonlinear regression analysis of the average observed } \\
\text { activity (in triplicate) versus inhibitor concentration data. }\end{array}$} \\
\hline \multicolumn{4}{|c|}{$\begin{array}{l}\text { c. In cases where analysis is limited by compound solubility, the minimum estimate of } \mathrm{IC}_{50} \text { is } \\
\text { provided, Values from Bhat et al. }{ }^{28}\end{array}$} \\
\hline \multicolumn{4}{|c|}{ d. Co(II) cofactors employed in assay } \\
\hline \multicolumn{4}{|c|}{ e. $\mathrm{Mn}$ (II) cofactors employed in assay } \\
\hline
\end{tabular}

\subsection{Host-Cell Viability Assay}

Based on the in silico and in vitro screens, a subset of 17 RpMetAP-inhibitory compounds was selected for testing against $R$. prowazekii growth in a cell culture model infection system (Table 6). Considering that $R$. prowazekii is a vasculotropic pathogen, we used primary pulmonary vascular endothelial cells (ECs) of rat origin for the infection studies. In order to design an assay that was compatible with working under BSL-3 conditions at moderate throughput, our strategy here was to use host cell viability as an indirect measure of rickettsial intracellular growth. Under typical infection conditions, rickettsiae grow inside the host cell to large numbers until the host cell succumbs to infection and lyses. Thus, any RpMetAP-inhibitory compound that inhibits rickettsial growth will protect host cell viability over the infection time course. To this end, we used a cell proliferation assay where the amount of water-soluble tetrazolium salt-1 (WST-1) metabolism directly correlates with the number of viable cells.

There are several noteworthy considerations pertaining to rickettsial obligate intracellular growth and our study design. Firstly, rickettsiae are not free-living organisms like $E$. coli. Rickettsiae cannot be grown in pure culture and thus, typical antibiotic resistance screening using, for example, Mueller-Hinton agar and disc diffusion susceptibility assays are not applicable. Secondly, because 
rickettsiae must grow inside of a eukaryotic host cell, it is not reasonable to design assays based on direct exposure of the pathogen to potential antibiotic compounds. A physiologically relevant screening system must consider the biology of both pathogen and host. This includes diffusion of compounds into the eukaryotic host cell cytoplasm and metabolism/break-down of the compounds by host cell metabolism. Lastly, it is important to note that due to their obligatory intracellular growth consideration of selective toxicity is of paramount importance. Any perturbations that adversely affect host EC health will indirectly result in $R$. prowazekii growth inhibition. Thus, great care was taken to determine the effects of solvents on R. prowazekii and EC viability, and to test for off-target effects of the RpMetAPinhibitory compounds on EC viability prior to screening against $R$. prowazekii-infected ECs. We first determined the optimal concentration of solvent (DMSO) used to dissolve the RpMetAP-inhibitory compounds that was non-toxic to both the ECs and R. prowazekii (optimal concentration was determined to be $0.3 \%$ DMSO, data not shown). We next tested the RpMetAP-inhibitory compounds over a range of concentrations ranges on uninfected ECs and identified concentration ranges that were non-toxic to the ECs (data not shown). Based on the solubility of the RpMetAP-inhibitory compounds in $100 \%$ DMSO and the preliminary EC toxicity screen, we selected the optimal concentration ranges for testing each of the 23 RpMetAP-inhibitory compounds against $R$. prowazekii-infected ECs (see Table 6). 
Table 6: RpMetAP Inhibitory Compounds Tested in EC Culture Infection Model

\begin{tabular}{|c|c|c|c|c|}
\hline Compound & $\mathrm{MW}^{\mathrm{a}}$ & Stock $(\mathrm{mM})^{b}$ & 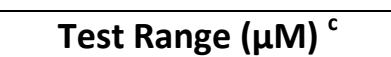 & Growth Inhibition \\
\hline (10) & 222.63 & 100 & $300,30,3,0.3$ & No \\
\hline (11) & 257.07 & 100 & $300,30,3,0.3$ & No \\
\hline (12) & 206.27 & 100 & $300,30,3,0.3$ & Yes \\
\hline (13) & 220.30 & 100 & $300,30,3,0.3$ & Yes \\
\hline (14) & 224.26 & 100 & $300,30,3,0.3$ & Yes \\
\hline (15) & 240.72 & 100 & $300,30,3,0.3$ & Yes \\
\hline (16) & 240.72 & 100 & $300,30,3,0.3$ & Yes \\
\hline (17) & 275.16 & 100 & $30,3,0.3,0.03$ & No \\
\hline (18) & 248.35 & 100 & $30,3,0.3,0.03$ & No \\
\hline (19) & 262.37 & 100 & $30,3,0.3,0.03$ & No \\
\hline (20) & 195.65 & 100 & $3,0.3,0.03,0.003$ & No \\
\hline (21) & 181.62 & 100 & $30,3,0.3,0.03$ & Yes \\
\hline (22) & 245.06 & 100 & $30,3,0.3,0.03$ & Yes \\
\hline (23) & 190.16 & 100 & $3,0.3,0.03,0.003$ & No \\
\hline (24) & 315.20 & 40 & $20,2,0.2,0.02$ & No \\
\hline (25) & 362.25 & 25 & $7.5,0.75,0.075,0.0075$ & No \\
\hline (26) & 325.75 & 100 & $3,0.3,0.03,0.003$ & Yes \\
\hline
\end{tabular}

a. Compound Molecular Weight in $\mathrm{g} / \mathrm{mol}$.

b. Stock inhibitor solutions were initially prepared in $100 \%$ DMSO to achieve a $100 \mathrm{mM}$ concentration. Compounds that were insoluble at $100 \mathrm{mM}$ were adjusted by addition of DMSO until solubility was achieved.

c. All compounds were initially tested for toxicity against uninfected ECs. Working concentration test ranges that produced no EC toxicity were selected for further testing against $R$. prowazekii-infected ECs.

d. Inhibition of rickettsial growth was determined using the in vitro host EC viability assay described in the Experimental Methods section. 


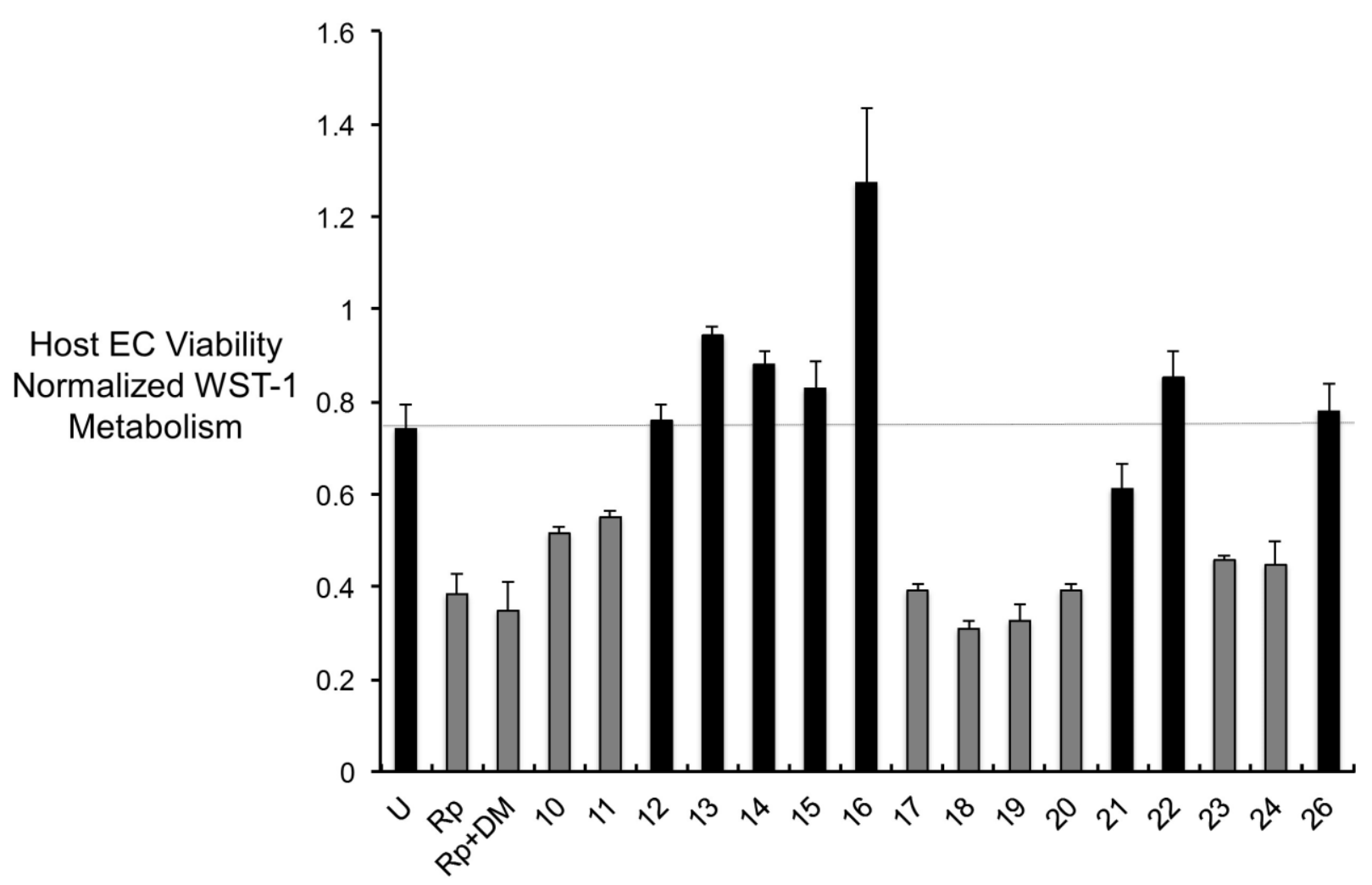

Figure 5: Effects of RpMetAP inhibitors on R. prowazekii growth. The loss of infected host ECs viability due to normal $R$. prowazekii growth was used to indirectly assess whether RpMetAP inhibitors produced antibacterial effects. The expectation here is that compounds inhibiting rickettsial growth will restore host EC viability to levels comparable to the uninfected control ECs. Host EC viability was measured via WST-1 metabolism (calculated as $\mathrm{A}_{450 \mathrm{~nm}}-\mathrm{A}_{660 \mathrm{~nm}}$ and normalized to media only as background). Solid black bars denote compounds that restored host EC viability to levels comparable to uninfected ECs (denoted by the dashed lines). $U$ = uninfected control ECs; $\mathrm{Rp}=R$. prowazekii-infected host $\mathrm{ECs} ; \mathrm{Rp}+\mathrm{DM}=R$. prowazekii-infected host ECs treated with the vehicle/solvent control (0.3\% DMSO); numbers denote compound identification from Table 6 . Infections were performed at a MOI $=100$ rickettsiae: 1 host cell. Results represent the average of triplicate infections \pm standard deviation.

Figure 5 shows the effects of each of the compounds at the maximal concentration tested. Control, uninfected EC monolayers were healthy and displayed robust WST-1 metabolism (solid black bar labeled U). When EC monolayers were infected with $R$. prowazekii (at an $\mathrm{MOI}=100: 1$ ), host EC metabolism of WST-1 was reduced 2-fold at 72 hours post-infection (solid grey bar labeled Rp), indicating that $R$. prowazekii intracellular growth reduced host EC viability. This result was confirmed visually under the microscope where monolayers looked stressed with the presence of visible cellular debris (data not shown). The combination of $R$. prowazekii infection and the addition of the solvent 
control (0.3\% DMSO) gave results comparable to infected ECs without DMSO (solid grey bar labeled Rp+DM). The remainder of Figure 5 and Table 6 show 10 promising RpMetAP-inhibitory compounds out of the 23 tested that restored $R$. prowazekii-infected EC viability to levels equal to or greater than the uninfected control ECs. The sensitivity of this viability assay was further assessed using EC monolayers infected with a lower burden of rickettsiae ( $\mathrm{MOI}=50: 1)$, which resulted in only a 1.2-fold reduction in host EC viability, and revealed a similar subset of RpMetAP-inhibitory compounds as restorative of host EC viability (data not shown).

When tested serially at 10-, 100- and 1000-fold dilutions, the RpMetAP-inhibitory compounds lost inhibitory efficacy indicating that the maximal concentration tested was the most effective at inhibiting R. prowazekii growth (data not shown). It is unknown as to whether permeability into the host ECs or compound metabolism/turnover played any role in the observed loss of efficacy. Again, it is noteworthy that inhibitory compounds will only exhibit anti-rickettsial activity via uptake by the host EC cells, followed by uptake by the obligate intracellular parasite cells; this assay therefore mimics practical application better than cases where suspected therapeutics are introduced to free-living pathogens.

Interestingly, the data in Figure 5 show several of the RpMetAP-inhibitory compounds stimulated host EC metabolism to levels greater than the control, uninfected and untreated cells. In fact, the preliminary screen of RpMetAP-inhibitory compounds for off-target toxicity on uninfected ECs revealed 8 of 23 compounds stimulated host EC metabolism (data not shown). The nature of this metabolic stimulatory effect is unknown. It is noteworthy that of the compounds that stimulated EC metabolism, only 4 were found to also inhibit rickettsial growth $(\mathbf{1 2}, \mathbf{1 5}, \mathbf{1 6}, \mathbf{2 2})$. However, studies with compound (16) visually demonstrate rickettsial death upon treatment (Figure 6). Together these data suggest that targeting $R$. prowazekii MetAP is selectively toxic to the rickettsiae and may represent a novel class of anti-rickettsial therapeutics. 
The furoic acid inhibitors were the most potent of the classes of compounds screened in the enzymatic assay, but did not restore $R$. prowazekii-infected host cell viability. The results of the host-cell viability assay therefore suggest furoic acid inhibitors are not readily permeable to host ECs, are not permeable to bacteria residing within host ECs, or the native cofactors of RpMetAP are not Mn(II). Considering that free carboxylic acids are known to exhibit minimal membrane permeability, the observed lack of anti-rickettsial activity is likely the result of poor cellular uptake. ${ }^{31}$ As such, compounds (6) and (8) were not screened for host-cell viability, although they exhibited similar activity as compounds (10) and (11) when screened against RpMetAP1.

All quinolinol-based RpMetAP1 inhibitory compounds were screened in the host-cell viability assay, regardless of the activity observed against the enzyme, because all but two compounds, (25-26), exhibited $\mathrm{IC}_{50}$ values less than $10 \mu \mathrm{M}$. Interestingly, three compounds from this chemical class were determined to restore $R$. prowazekii-infected host cell viability. Two were unsubstituted 8-quinolinol derivatives $(\mathbf{2 1}, \mathbf{2 2})$ while the remaining compound (26) was a Mannich derivative of nitroxoline (23).

The most effective compounds for restoring host-cell viability were from the 1,2,4-triazole series. Because these compounds were determined to exhibit similar inhibitory activities against the RpMetAP1 target, all eight analogs from this series were tested and five exhibited anti-rickettsial activity (12 - 16) while restoring host-cell viability. The three analogs (17 - 19) that did not restore host-cell viability contained lipophilic substituents that increased their CLogP values and lowered their solubility.

Finally, we assayed compound (16), which both inhibited RpMetAP1 activity and stimulated host EC metabolism, to investigate whether the compound inhibited rickettsial growth by fluorescence staining and microscopy to provide a visual representation of the observed effects. For these experiments, doxycycline was included as a clinically relevant positive control to inhibit rickettsial intracellular growth. Figure 6A shows a healthy, uninfected and untreated control EC monolayer with 
Hoechst-stained nuclei (blue pseudocolor) and phalloidin-stained actin outlining cell boundaries (red pseudocolor). Figure 6B shows the presence of several host ECs infected with intracellular, rod shaped $R$. prowazekii stained with an anti-rickettsial antibody (green pseudocolor). Figure 6C shows treatment of infected host ECs with compound (16) resulted in identification of intracellular debris that stained with the anti-rickettsial antibody but did not resemble healthy, rod-shaped bacteria shown in Figure 6B; this data strongly suggests that intracellular rickettsial growth abatement had occurred. We confirmed visually that addition of compound (16) alone had no overt effect on the appearance of the monolayers (data not shown). Moreover, a similar pattern of staining with the anti-rickettsial antibody was also observed when infected ECs were treated with doxycycline as a positive control known to inhibit rickettsial growth (Figure 6D). Together, these results confirm the promise of compound (16) as representative of a novel class of anti-rickettsial therapeutics that do not appear to have overt deleterious effects on host EC ultrastructure by fluorescence staining and microscopy. 

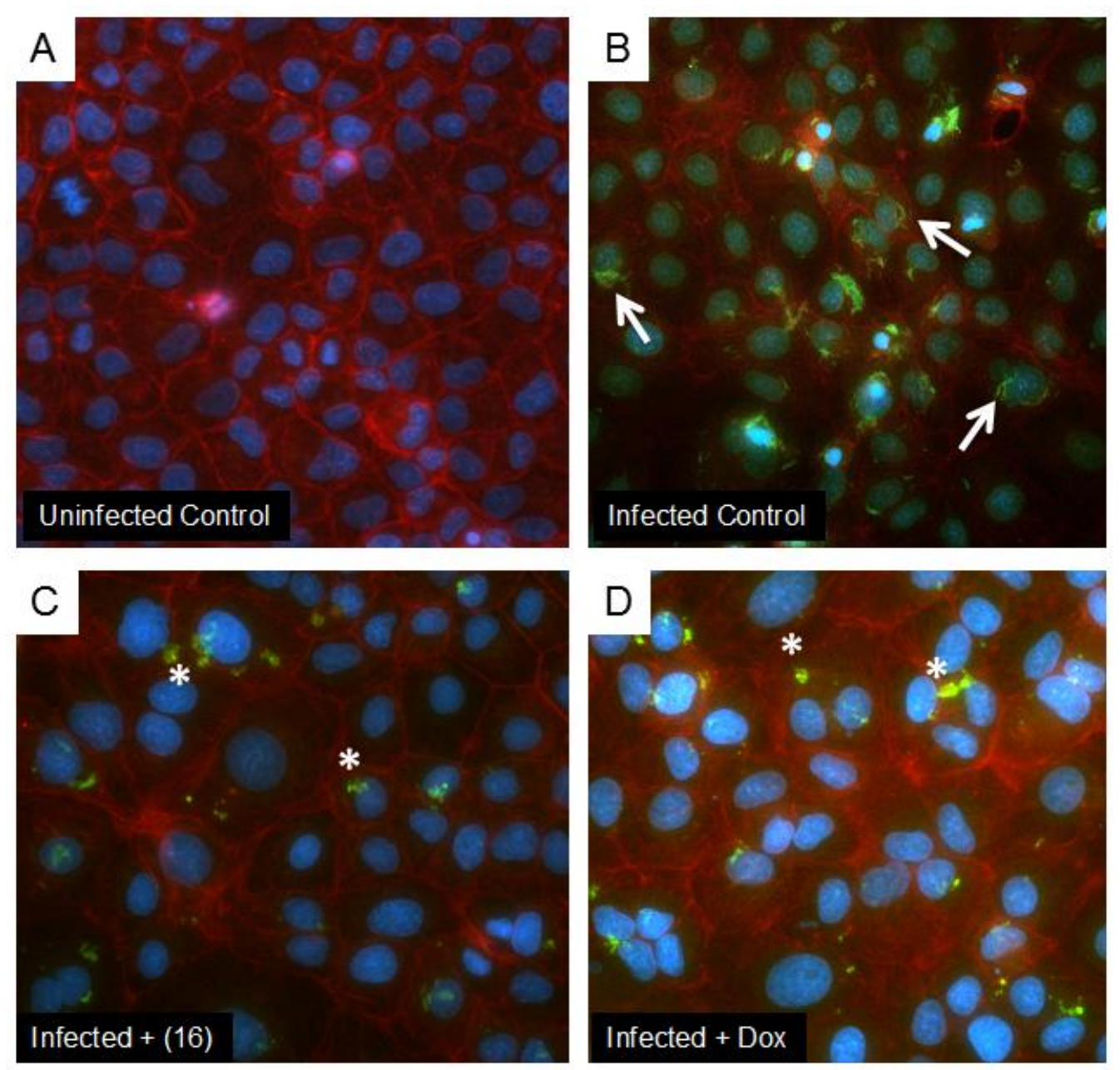

Figure 6: Representative fluorescent micrographs showing effects of RpMetAP inhibitor compound (16) compared to a doxycycline control. Panel A shows uninfected control ECs. Panel B shows ECs infected with $R$. prowazekii. Panel C shows the effects of treating $R$. prowazekii-infected ECs with compound (16) (300 $\mu \mathrm{M}$ final concentration). Panel D shows the effects of treating $R$. prowazekii-infected ECs with doxycycline $(25 \mu \mathrm{g} / \mathrm{mL})$ as a positive control. Uninfected control cells show very little background antibody staining. The infected control shows infection with many bacilli (white arrows). Treatment with either inhibitor caused bacterial shape changes consistent with condensation and death (white asterisk). Nuclei were stained with Hoescht (blue pseudocolor); actin was stained with Texas Red-labeled Phaloidin (red pseudocolor); and rickettsiae were stained with a specific antibody conjugated to FITC (green pseudocolor). 


\section{Conclusions}

A series of compounds based upon furoic acid, 1,2,4-triazole, and quinolinol motifs were synthesized or purchased and screened for enzymatic inhibitory activity against $R$. prowazekii MetAP. Suspected RpMetAP1 inhibitory compounds were first screened against the enzyme in a fluorescencebased activity assay, with $\mathrm{Mn}(\mathrm{II})$ utilized as the enzymatic cofactors. It was determined that compounds based upon all three scaffolds exhibited potent inhibitory activity. The most active compounds were subjected to a host cell viability assay to determine anti-Rickettsial activity in the presence of host endothial cells, which revealed only quinolinol and triazole-based inhibitors were active at "reasonable" concentrations. The lack of observed activity from the furoic acid series may be due to limited membrane permeability of small molecules containing free acid groups. The most potent compound in the host-cell viability assay was 2-chlorophenyl 1,2,4-triazole derivative (16) and the activity of this compound was therefore monitored with fluorescence staining and microscopy to provide a visual representation of the anti-Rickettsial activity in the presence of mammalian host-cells. These data suggest that compounds based upon both the 1,2,4-triazole and quinolinol scaffolds exhibit efficacy against the intracellular pathogen while allowing the restoration of host-cell viability. Thus, compounds of these classes should be optimized against RpMetAP1 and the resulting species should be re-screened to determine anti-Rickettsial activity in the presence of mammalian host-cells.

\section{Experimental}

\subsection{Crystallization and Data Collection}

Purified RpMetAPs were screened for crystallization in 96-well sitting-drop plates against the JCSG+ and PACT crystal screens (Rigaku Reagents). Equal volumes of protein solution (0.4 $\mu \mathrm{l}$ ) and precipitant solution were set up at $293 \mathrm{~K}$ against reservoir $(80 \mu \mathrm{l})$ in sitting-drop vapor-diffusion format. 
The A4 construct crystallized in the PACT screen condition G8 which contains $0.2 \mathrm{M}$ sodium sulfate, 0.1 M BisTris propane $\mathrm{pH} 7.5$, and $20 \% \mathrm{w} / \mathrm{v}$ PEG 3350. The A6 construct crystallized in the PACT screen condition A6 which contains 0.1 M SPG (succinic acid, phosphate, glycine) buffer pH 8.0 and 25\% w/v PEG 1500. The crystals were cryo-protected in crystallant plus $25 \% \mathrm{v} / \mathrm{v}$ 1,2-ethanediol and cryo-cooled by dipping into liquid nitrogen. Data were collected under the Collaborative Crystallography program of the Berkeley Center for Structural Biology at the Advanced Light Source, Berkeley National Laboratory. Data were collected at $100^{\circ} \mathrm{C}$ on Advanced Light Source beamline 5.0.1 using an ADSC Quantum 315 CCD detector with $1^{\circ}$ oscillations at a wavelength of $0.9774 \AA$. Data were reduced with HKL2000 ${ }^{32}$. Raw X-ray diffraction images are available at the Integrated Resource for Reproducibility in Macromolecular Crystallography at www.proteindiffraction.org.

\subsection{Structure Solution and Refinement}

The structure was solved by molecular replacement with Phaser from the CCP4 suite of programs using PDB entry $1 X N Z^{12}$ as a search model. ${ }^{33}$ The structure was refined using iterative cycles of Refmac5 followed by manual rebuilding of the structure using Coot. ${ }^{34}$ The quality of all of the structures was assessed using MolProbity. ${ }^{35}$ All data-reduction, refinement, and data collection statistics can be found in Table S3. Structure figures were analyzed and prepared using PyMOL (v.1.5; Schrodinger) and PISA. Coordinates and structure factors have been deposited with the Protein Data Bank (PDB) (http://www.rcsb.org/pdb/home/home.do) with accession number 3MR1 and 3MX6. 


\subsection{RpMetAP Cloning and Purification}

Cloning, expression and purification were conducted as part of the Seattle Structural Genomics Center for Infectious Disease (SSGCID) following standard protocols described previously. ${ }^{36}$ All constructs of RpMetAP (Uniprot: Q9ZCD3) were PCR-amplified from Rickettsia prowazekii str. Madrid E kindly provided by Dr. David H. Walker. A full length (1-259) and five variant open reading frames (ORF) were cloned into the ligation independent cloning (LIC) expression vector pAVA0421 encoding a cleavable $6 \mathrm{xH}$ is fusion tag followed by the human rhinovirus $3 \mathrm{C}$ protease-cleavage sequence (MAHHHHHHMGTLEAQTQGPGSM) followed by the ORF. ${ }^{37}$ The human rhinovirus $3 \mathrm{C}$ protease-cleavage site is between the glutamine and glycine residues that are underlined. An additional full length construct was cloned into the expression vector pBG1861 which encodes a non-cleavable 6xHis fusion tag (MAHHHHHH). See Supplemental Information, Table S2 for list of constructs. Complete amino acid sequences are included in supplementary materials.

Plasmid DNA was transformed into chemically competent E. coli BL21 (DE3) R3 Rosetta cells. Cells were expression tested in 96 well blocks according to the procedures described in Choi, et al.,

2011. ${ }^{36 e}$ Briefly, cells are inoculated into $600 \mu \mathrm{l}$ ZYP-5052 auto-induction medium [Sterile ZY Broth (10 g/L tryptone, $5 \mathrm{~g} / \mathrm{L}$ yeast extract), $1 \mathrm{mM} \mathrm{MgSO}$, $1 \times$ metals mix, $1 \times 5052$ (0.5\% glycerol, $0.05 \%$ glucose, $0.2 \% \alpha$-lactose monohydrate) and $1 \times$ NPS] supplemented with the correct antibiotics. The block was sealed and incubated on a plate shaker inside a refrigerated incubator set at $293 \mathrm{~K}$ for roughly $27 \mathrm{~h}$ to allow the cultures to reach saturation or early stationary phase. The cultures were not harvested until OD600nm readings of at least 0.6 were obtained. Once the induced cells were at the correct density, they were centrifuged at $4{ }^{\circ} \mathrm{C}$ and $4300 \mathrm{rpm}$ for $30 \mathrm{~min}$. After centrifugation, the supernatant was discarded and the block with the semi-dry cell pellets were stored at $193 \mathrm{~K}$. Cell pellets were analyzed for expression of insoluble and soluble RpMetAP by re-suspension in $600 \mu$ l lysis buffer [ 20 mM HEPES pH 7.0, 500 mM NaCl, 5\% glycerol, 0.5\% CHAPS (A.G. Scientific Inc., San Diego, California, USA), 30 mM 
imidazole, $10 \mathrm{mM} \mathrm{MgCl2}, 400 \mu \mathrm{g} \mathrm{ml-1}$ lysozyme (Sigma, St Louis, Missouri, USA) and 3 units/mL Benzonase nuclease (EMD Chemicals, San Diego, California, USA). After resuspension, $600 \mu$ lysis buffer was added to each well and the sample was mixed a second time. The deep well block was then sealed and incubated at room temperature for $1 \mathrm{~h}$ on a titer shaker set to moderate. The block was clarified by centrifugation at $4300 \mathrm{rev} \min -1$ for $30 \mathrm{~min}$. Soluble and insoluble fractions were analyzed by SDS-PAGE for bands of appropriate MW. Only RpMetAP constructs which showed soluble expressed protein progressed into further large scale fermentation and purification. Constructs B1, A4 and A6 (see Table S2) expressed soluble protein and were further upscaled and purified by IMAC and Size exclusion chromatography (SEC) as described previously. ${ }^{36 e}$ Proteins were concentrated and stored in the final SEC running buffer was composed of $20 \mathrm{mM}$ HEPES $\mathrm{pH} 7,0.3 \mathrm{M} \mathrm{NaCl}, 5 \%$ glycerol, $1 \mathrm{mM}$ TCEP. Aliquots of $100 \mu \mathrm{l}$ were cryo-cooled in liquid nitrogen and stored at $-80^{\circ} \mathrm{C}$ until use for crystallization.

\subsection{Enzymatic Assay}

The assay utilized is similar to that which we reported earlier. ${ }^{11,18}$ The fluorogenic peptide substrate, methionine-aminomethylcoumarin was purchased from Enzo Life Sciences (Farmingdale, NY). Purified RpMetAP1a was obtained from the Seattle Structural Genomics Center for Infectious Disease (SSGCID) and was used as received. Enzyme stock solutions were prepared by diluting RpMetAP1a into assay buffer (6.25 mM HEPES, $0.1 \mathrm{mM} \mathrm{MnCl}_{2}, 125 \mathrm{mM} \mathrm{NaCl}, \mathrm{pH} 7.0$ ) and adjusting enzyme concentration to $4 \mu \mathrm{M}$, where concentration was determined from solution absorbance at $250 \mathrm{~nm}$ (measured with a Thermo Scientific NanoDrop 2000c, extinction coefficient $=30,370 \mathrm{M}^{-1} \mathrm{~cm}^{-1}$ ). Enzymatic activity of RpMetAP was followed using a Synergy 2 Plate reader (Biotek, Winooski, Vt). All kinetic experiments were performed using Nunc flat-bottom maxisorp 96-well plates (Thermo Fisher Scientific, Rochester, NY). Each well contained $80 \mu \mathrm{L}$ of assay mixture with final concentrations of 6.25 
mM HEPES, $0.1 \mathrm{mM} \mathrm{MnCl}$, $125 \mathrm{mM} \mathrm{NaCl}, 200 \mu \mathrm{M}$ Met-AMC, $1.0 \mu \mathrm{M}$ RpMetAP1, and 1\% DMSO at pH 7.0 and at various inhibitor concentrations. First, enzyme from prepared stock solutions $(20 \mu \mathrm{L})$ and inhibitors at variable concentrations ( $20 \mu \mathrm{L}, 4 \% \mathrm{DMSO})$ in assay buffer was centrifuged $\left(4^{\circ} \mathrm{C}, 2000 \mathrm{rpm}\right.$, $5 \mathrm{~min})$ and incubated for $1 \mathrm{~h}$ at $4^{\circ} \mathrm{C}$. Then, substrate $(40 \mu \mathrm{L}, 400 \mu \mathrm{M})$ in assay buffer was added to each well, centrifuged $\left(4{ }^{\circ} \mathrm{C}, 2000 \mathrm{rpm}, 5 \mathrm{~min}\right)$, and incubated at $30{ }^{\circ} \mathrm{C}$ in the plate reader for $30 \mathrm{~min}$. The fluorescent emission resulting from the cleavage of Met-AMC was monitored for 90 min (Excite: $360 \mathrm{~nm}$, Read: $460 \mathrm{~nm}$ ). Relative activities of enzyme/substrate solutions were determined as the slope of inhibited enzyme divided by the slope of free enzyme. The first 30 min of data were discarded as this was considered condition equilibration. Inhibitory activities were calculated as the ratio of inhibited and uninhibited enzyme activity $\left(v_{i} / v_{0}\right)$ and dose-response curves were fit according to published methods. $^{38}$

\subsection{Molecular Docking}

Detailed information regarding the validation of this docking method can be found in the supplemental information submitted with this manuscript. Briefly, ligand structures were composed in ChemDraw and the minimum energy conformation was calculated with Chem3D. These were used as the initial ligand conformations for docking. Grid box dimensions were $(50,50,50)$ and were centered between the metal cofactors for both structures (coordinates $(x, y, z)$ : EcMetAP: $(2.258,0.561,9.365)$; RpMetAP: (11.561, -12.202, 9.441)). Docking output was evaluated based upon both the predicted docking poses and predicted binding affinities $\left(\mathrm{K}_{\mathrm{i}}\right)$. 


\subsection{R. prowazekii Infection of Cultured Pulmonary Vascular Endothelial Cells and Treatment with}

\section{RpMetAP Inhibitory Compounds}

All infection experiments described in this study used the virulent $R$. prowazekii strain Breinl propagated in and isolated from hen egg yolk sacs (Audia laboratory passage \#3) as previously described ${ }^{39}$ with the $^{3}$ modifications described in. ${ }^{40}$ Post-isolation, $R$. prowazekii were suspended in a solution consisting of $220 \mathrm{mM}$ sucrose, $12 \mathrm{mM}$ potassium phosphate, $4.9 \mathrm{mM}$ potassium glutamate, and $10 \mathrm{mM}$ magnesium chloride, $\mathrm{pH} 7.0$ $\left(\mathrm{SPGMg}^{2+}\right)$ and stored as frozen aliquots at $-80{ }^{\circ} \mathrm{C}$ until used. Post-thaw on ice, total infectious organisms per $\mathrm{mL}$ of suspension were determined using the modified hemolysis assay of Winkler and Walker, ${ }^{41}$ which was subsequently used to calculate experimental multiplicities of infection (MOI). All manipulations of infectious $R$. prowazekii were performed under BSL-3 conditions.

Primary pulmonary vascular endothelial cells (ECs) of CD rat origin were isolated and characterized as previously described. ${ }^{42}$ For the studies described here, cultured ECs of low passage number $(<15)$ were kindly provided by the University of South Alabama Center for Lung Biology Cell Culture Core. ECs were routinely cultured as adherent monolayers in plastic culture dishes (at $37^{\circ} \mathrm{C}, 5 \% \mathrm{CO}_{2}$, atm $\mathrm{O}_{2}$ ) in DMEM high glucose medium (without phenol red) supplemented with $10 \%$ fetal bovine serum and $4 \mathrm{mM}$ L-glutamine (DMEM/FBS). For all experiments, ECs suspended in DMEM/FBS were stained with erythrosin B ( $0.025 \%$ final concentration) and enumerated in a Fuchs-Rosenthal counting chamber prior to seeding.

To prepare ECs for infection, $2.5 \times 10^{4}$ total ECs (per $0.1 \mathrm{~mL}$ DMEM/FBS) were seeded in 96-well culture plates and incubated overnight to allow for adherence and monolayer formation ( 18 hours, at $37^{\circ} \mathrm{C}, 5 \% \mathrm{CO}_{2}$, atm $\mathrm{O}_{2}$ ). A frozen aliquot of $R$. prowazekii was thawed on ice, diluted in DMEM/FBS to give a concentration of infectious rickettsiae per $0.1 \mathrm{~mL}$ equivalent to a $\mathrm{MOI}$ of either 100 rickettsiae per host cell (100:1) or 50 rickettsia per cell (50:1). The DMEM/FBS seeding medium was removed from each well and replaced with $0.1 \mathrm{~mL}$ of rickettsiaecontaining medium to initiate infection. Control, uninfected wells received only DMEM/FBS. Culture plates were then returned to the incubator (at $37^{\circ} \mathrm{C}, 5 \% \mathrm{CO}_{2}$, atm $\mathrm{O}_{2}$ ).

At 24-hours post-infection the culture medium was removed from each well and replaced with $0.1 \mathrm{~mL}$ of: 1) DMEM/FBS only (control), 2) DMEM/FBS containing 0.3\% DMSO (RpMetAP inhibitory compound solvent/vehicle 
control), or 3) DMEM/FBS containing RpMetAP inhibitory compounds (see Table 6 and Results and Discussion section for concentrations tested). Culture plates were returned to the incubator $\left(37^{\circ} \mathrm{C}, 5 \% \mathrm{CO}_{2}\right.$, atm $\left.\mathrm{O}_{2}\right)$. All conditions were tested in triplicate and monolayers were visually inspected by light microscopy every 18-20-hours subsequently.

At 72-hours post-infection (corresponding to 48-hours post-compound addition), host EC viability was determined using Roche's WST-1 cell proliferation reagent. A ratio of $1 \mathrm{~mL}$ WST-1 reagent was added per $10 \mathrm{~mL}$ DMEM/FBS medium (now DMEM/FBS+WST-1) and mixed thoroughly by pipetting. Culture medium was removed from each well and replaced with $0.11 \mathrm{~mL}$ of DMEM/FBS+WST-1. Culture plates were returned to the incubator for 60-minutes (at $37^{\circ} \mathrm{C}, 5 \% \mathrm{CO}_{2}$, atm $\mathrm{O}_{2}$ ). A volume of $0.015 \mathrm{~mL}$ of $37 \%$ formaldehyde solution was added to each well to stop the WST-1 reaction and fix-kill the rickettsiae. We verified that the addition of formaldehyde did not adversely affect the WST-1 signal compared to wells that were not formaldehyde-treated (data not shown). Culture plates were returned to the incubator for an additional 20 -minutes (at $37^{\circ} \mathrm{C}, 5 \% \mathrm{CO}_{2}$, atm $\mathrm{O}_{2}$ ). The amount of WST-1 metabolism was determined as per the manufacturer's directions using a microplate reader and medium only wells (with no cells) were also included on the culture plate for background subtraction. Data were plotted as the mean normalized WST-1 signal \pm standard deviation.

\subsection{Assessment of $R$. prowazekii Growth Inhibition by Compound (16) Using Fluorescent Microscopy}

In order to provide a visual account of the effects of RpMetAP inhibitory compounds on R. prowazekii intracellular growth, a separate set of infection experiments were performed and slides prepared for staining and fluorescent microscopic analysis. To prepare ECs for infection, $2.5 \times 10^{4}$ total ECs (per $0.2 \mathrm{~mL}$ DMEM/FBS) were seeded in 8-well glass chamber slides and incubated overnight to allow adherence and monolayer formation ( 18 hours, at $37^{\circ} \mathrm{C}, 5 \% \mathrm{CO}_{2}$, atm $\mathrm{O}_{2}$ ). As described above, ECs were subsequently mock-infected (DMEM/FBS only) or infected with R. prowazekii (MOI 50:1) and chamber slides returned to the incubator (at $37^{\circ} \mathrm{C}, 5 \% \mathrm{CO}_{2}$, atm $\mathrm{O}_{2}$ ). Note that infections were adjusted to a $0.2 \mathrm{~mL}$ final volume. 
At 24-hours post-infection the culture medium was removed from each chamber well and replaced with $0.2 \mathrm{~mL}$ of: 1) DMEM/FBS only (control), 2) DMEM/FBS containing $300 \mu \mathrm{M}$ compound (16), or 3) DMEM/FBS containing $25 \mu \mathrm{g} / \mathrm{mL}$ doxycycline (positive control). All conditions were tested in duplicate. Chamber slides were returned to the incubator $\left(37^{\circ} \mathrm{C}, 5 \% \mathrm{CO}_{2}\right.$, atm $\left.\mathrm{O}_{2}\right)$.

At 72-hours post-infection the culture medium was removed from each chamber well and replaced with $0.3 \mathrm{~mL}$ of fixative solution (phosphate buffered saline, $\mathrm{pH} 7.4$ [PBS] containing $2.5 \%$ formaldehyde). Chamber slides were kept in the biosafety cabinet under ambient conditions for 20-minutes to allow fixation to occur.

To prepare slides for staining, fixative solution was removed and chamber wells were washed once with $0.3 \mathrm{~mL}$ PBS. The PBS was discarded, $0.1 \mathrm{~mL}$ of blocking solution (PBS containing $0.2 \%$ Triton X-100, 10\% normal goat serum) added, and chamber slides incubated for 20-minutes under ambient conditions. The blocking solution was discarded, $0.1 \mathrm{~mL}$ of staining solution (blocking solution containing 1 Mg/mL Hoescht 33258, $0.2 \mathrm{U}$ Texas Red labeled phalloidin, 1:2000 dilution of a FITC-labeled antibody specific to $R$. prowazekii) added, and chamber slides incubated for 45-minutes under ambient conditions (foil wrapped). The staining solution was discarded and slides

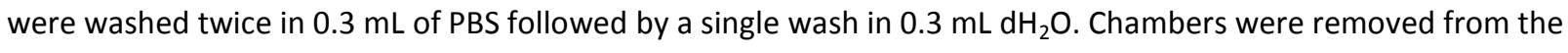
slide, a large glass coverslip (50 mm) was mounted using Invitrogen's Prolong AntiFade medium as per the manufacturer's directions, and slides were allowed to cure overnight under ambient conditions (foil wrapped). Individual images for each fluorescent compound within the same field of view were captured using a Nikon Eclipse Ni microscope with Nikon Elements software. Individual images were overlaid, converted to pseudocolor and brightness and contrast adjusted using Adobe Photoshop. Hoescht-stained nuclei are pseudocolored blue, phalloidin-stained actin cytoskeleton is pseudocolored red and intracellular rickettsiae are pseudocolored green.

\section{Acknowledgments}

This project has been funded in part with Federal funds from the National Institute of Allergy and Infectious Diseases, National Institutes of Health, Department of Health and Human Services, under Contract Nos. HHSN272200700057C and HHSN272201200025C. The Berkeley Center for Structural Biology is supported in part by the National Institutes of Health, National Institute of General Medical Sciences, and the Howard Hughes 
Medical Institute. The Advanced Light Source is supported by the Director, Office of Science, Office of Basic Energy

Sciences, of the U.S. Department of Energy under Contract No. DE-AC02-05CH11231. Finally, the authors would

like to acknowledge funding from the NIH for construction of the BSL-3 facility at the University of South Alabama

(Contract No. C06 RR029870) and for the procurement of a microscope utilized in this study (Contract No. K22

Al089786).

\section{References}

1. Bechah, Y.; Capo, C.; Raoult, D.; Mege, J. L., J. Infect. Dis. 2008, 197, 142.

2. Audia, J. P., Rickettsial Physiology and Metabolism in the Face of Reductive Evolution. In Intracellular Pathogens II: Rickettsiales, American Society of Microbiology: 2012.

3. (a) Andersson, J. O.; Andersson, S. G. E., Res. Microbiol. 2000, 151, 143; (b) Raoult, D.; Woodward, T.; Dumler, J. S., Infect. Dis. Clin. North Am. 2004, 18, 127.

4. Zhu, Y.; Fournier, P. E.; Ogata, H.; Raoult, D. J,. Clin. Microbiol. 2005, 43, 4708.

5. Birg, M. L.; La Scola, B.; Roux, V.; Brouqui, P.; Raoult, D., J. Clin. Microbiol. 1999, $37,3722$.

6. Walker, D. H., Ann. N. U. Acad. Sci. 2003, 990, 739.

7. Walker, D. H., Clin. Infect. Dis. 2007, 45, S39.

8. Walker, D. H., Vaccine. 2009, 27, D52.

9. Weiss, E.; Dressler, H. R., J. Bacteriol. 1962, 83, 409.

10. Chang, S. Y.; McGary, E. C.; Chang, S., J. Bacteriol. 1989, 171, 4071.

11. Wangtrakuldee, P.; Byrd, M. S.; Campos, C. G.; Henderson, M. W.; Zhang, Z.; Clare, M.; Masoudi, A.; Myler, P. J.; Horn, J. R.; Cotter, P. A.; Hagen, T. J., ACS Med. Chem. Lett. 2013, 4, 699.

12. Ye, Q. Z.; Xie, S. X.; Huang, M.; Huang, W. J.; Lu, J. P.; Ma, Z. Q., J. Am. Chem. Soc. 2004, 126, 13940.

13. Arya, T.; Reddi, R.; Kishor, C.; Ganji, R. J.; Bhukya, S.; Gumpena, R.; McGowan, S.; Drag, M.; Addlagatta, A., J. Med. Chem. 2015, 58, 2350.

14. Zheng, H.; Chruszcz, M.; Lasota, P.; Lebioda, L.; Minor, W., J. Inorg. Biochem. 2008, $102,1765$.

15. Zheng, H.; Chordia, M. D.; Cooper, D. R.; Chruszcz, M.; Müller, P.; Sheldrick, G. M.; Minor, W., Nat. Protoc. 2014, 9, 156.

16. Helgren, T. R.; Wangtrakuldee, P.; Staker, B. L.; Hagen, T. J., Curr. Top. Med. Chem. 2016, $16,397$.

17. (a) Baell, J. B.; Holloway, G. A., J. Med. Chem. 2010, 53, 2719; (b) Baell, J. B., J. Nat. Prod. 2016, 79, 616; (c) Baell, J. B. W., Michael A., Nature. 2014, 513, 481.

18. Lu, J. P.; Ye, Q.-Z., Bioorg. Med. Chem. Lett. 2010, 20, 2776.

19. Lu, J. P.; Chai, S. C.; Ye, Q.-Z., J. Med. Chem. 2010, 53, 1329.

20. (a) Chai, S. C.; Ye, Q. Z., Bioorg. Med. Chem. Lett. 2010, 20, 2129; (b) Huang, Q. Q.; Huang, M.; Nan, F. J.; Ye, Q. Z., Bioorg. Med. Chem. Lett. 2005, 15, 5386; (c) Huguet, F.; Melet, A.; Alves de Sousa, R.; Lieutaud, A.; Chevalier, J.; Maigre, L.; Deschamps, P.; Tomas, A.; Leulliot, N.; Pages, J. M.; Artaud, I., ChemMedChem. 2012, 7, 1020; (d) Vedantham, P.; Guerra, J. M.; Schoenen, F.; Huang, M.; Gor, P. J.; Georg, G. I.; Wang, J. L.; Neuenswander, B.; Lushington, G. H.; Mitscher, L. A.; Ye, Q. Z.; Hanson, P. R., J. Combi. Chem. 2008, 10, 185; (e) Xie, S. X.; Huang, W. J.; Ma, Z. Q.; Huang, M.; Hanzlik, R. P.; Ye, Q. Z., Acta Crystallogr. Sect. D. 2006, 62, 425; (f) Huang, M.; Xie, S. X.; Ma, Z. Q.; Huang, Q. Q.; Nan, F. J.; Ye, Q. Z., J. Med. Chem. 2007, 50, 5735; (g) Chai, S. C.; Wang, W. L.; Ye, Q. Z., J. Biol. Chem. 2008, 283, 26879.

21. Yuan, H.; Chai, S. C.; Lam, C. K.; Howard Xu, H.; Ye, Q. Z., Bioorg. Med. Chem. Lett. 2011, $21,3395$.

22. (a) Mitra, S.; Sheppard, G.; Wang, J.; Bennett, B.; Holz, R., J. Biol. Inorg. Chem. 2009, 14, 573; (b) Oefner, C.; Douangamath, A.; D'Arcy, A.; Häfeli, S.; Mareque, D.; Mac Sweeney, A.; Padilla, J.; Pierau, S.; Schulz, H.; Thormann, M.; Wadman, S.; Dale, G. E., J. Mol. Biol. 2003, 332, 13-21. 
23. Marino, J. P.; Fisher, P. W.; Hofmann, G. A.; Kirkpatrick, R. B.; Janson, C. A.; Johnson, R. K.; Ma, C.; Mattern, M.; Meek, T. D.; Ryan, M. D.; Schulz, C.; Smith, W. W.; Tew, D. G.; Tomazek, T. A.; Veber, D. F.; Xiong, W. C.; Yamamoto, Y.; Yamashita, K.; Yang, G.; Thompson, S. K., J. Med. Chem. 2007, 50, 3777.

24. Olaleye, O.; Raghunand, T. R.; Bhat, S.; Chong, C.; Gu, P.; Zhou, J.; Zhang, Y.; Bishai, W. R.; Liu, J. O., Tuberculosis. 2011, 91, S61.

25. (a) Chai, S. C.; Ye, Q. Z., Bioorg. Med. Chem. Lett. 2009, 19, 6862; (b) Huang, M.; Xie, S. X.; Ma, Z. Q.; Hanzlik, R. P.; Ye, Q. Z., Biochem. Biophys. Res. Commun. 2006, 339, 506; (c) Altmeyer, M. A.; Marschner, A.; Schiffmann, R.; Klein, C. D., Bioorg. Med. Chem. Lett. 2010, 20, 4038.

26. Morris, G. M.; Huey, R.; Lindstrom, W.; Sanner, M. F.; Belew, R. K.; Goodsell, D. S.; Olson, A. J., J. Comput. Chem. 2009, 30, 2785.

27. Ma, Z. Q.; Xie, S. X.; Huang, Q. Q.; Nan, F. J.; Hurley, T. D.; Ye, Q. Z., BMC Struct. Biol. $2007,7,1$.

28. Bhat, S.; Shim, J. S.; Zhang, F.; Chong, C. R.; Liu, J. O., Org. Biomol. Chem. 2012, 10, 2979.

29. Wang, J.; Sheppard, G. S.; Lou, P.; Kawai, M.; Park, C.; Egan, D. A.; Schneider, A.; Bouska, J.; Lesniewski, R.; Henkin, J., Biochemistry. 2003, 42, 5035.

30. (a) Sato, Y., Biol. Pharm. Bull. 2004, 27, 772; (b) Benny, O.; Fainaru, O.; Adini, A.; Cassiola, F.; Bazinet, L.; Adini, I.; Pravda, E.; Nahmias, Y.; Koirala, S.; Corfas, G.; D'Amato, R. J.; Folkman, J., Nat. Biotech. 2008, $26,799$.

31. Ballatore, C.; Huryn, D. M.; Smith, A. B., ChemMedChem. 2013, 8, 385.

32. Otwinowski, Z.; Minor, W., Processing of X-ray diffraction data collected in oscillation mode. Elsevier: 1997; Vol. 276, pp 307-326.

33. (a) McCoy, A. J.; Grosse-Kunstleve, R. W.; Adams, P. D.; Winn, M. D.; Storoni, L. C.; Read, R. J., J. Appl. Crystallogr. 2007, 40, 658; (b) Winn, M. D.; Ballard, C. C.; Cowtan, K. D.; Dodson, E. J.; Emsley, P.; Evans, P. R.; Keegan, R. M.; Krissinel, E. B.; Leslie, A. G. W.; McCoy, A.; McNicholas, S. J.; Murshudov, G. N.; Pannu, N. S.; Potterton, E. A.; Powell, H. R.; Read, R. J.; Vagin, A.; Wilson, K. S., Acta Crystallogr. Sect. D. 2011, 67, 235.

34. (a) Vagin, A. A., Steiner, R.A., Lebedev, A.A., Potterton, L., McNicholas, S., Long, F., Murshudov, G.N., Acta. Crystallogr. Sect. D. 2004, 60, 2184; (b) Emsley, P.; Lohkamp, B.; Scott, W. G.; Cowtan, K., Acta Crystallogr. Sect. D. 2010, 66, 486.

35. Chen, V. B.; Arendall, W. B.; Headd, J. J.; Keedy, D. A.; Immormino, R. M.; Kapral, G. J.; Murray, L. W.; Richardson, J. S.; Richardson, D. C., Acta Crystallogr. Sect. D. 2010, 66, 12.

36. (a) Myler, P. J.; Stacy, R.; Stewart, L.; Staker, B. L.; Van Voorhis, W. C.; Varani, G.; Buchko, G. W., Infect. Disord. Drug. Targets. 2009, 9, 493; (b) Stacy, R.; Begley, D. W.; Phan, I.; Staker, B. L.; Van Voorhis, W. C.; Varani, G.; Buchko, G. W.; Stewart, L. J.; Myler, P. J., Acta Crystallogr. Sect. D. 2011, 67, 979; (c) Serbzhinskiy, D. A., Clifton, M.C., Sankaran, B., Staker, B.L., Edwards, T.E., Myler, P.J, Acta Crystallogr. Sect. F. 2015, 71, 594; (d) Bryan, C. M.; Bhandari, J.; Napuli, A. J.; Leibly, D. J.; Choi, R.; Kelley, A.; Van Voorhis, W. C.; Edwards, T. E.; Stewart, L. J., Acta Crystallogr. Sect. F. 2011, 67, 1010; (e) Choi, R.; Kelley, A.; Leibly, D.; Nakazawa Hewitt, S.; Napuli, A.; Van Voorhis, W., Acta. Crystallogr. Sect. F. 2011, 67, 998.

37. Aslanidis, C.; de Jong, P. J., Nucleic Acids. Res. 1990, 18, 6069.

38. Grant, S. K.; Sklar, J. G.; Cummings, R. T., J. Biomol. Screen. 2002, 7, 531.

39. Bovarnick, M. R.; Snyder, J. C., J. Exp. Med. 1949, 89, 561.

40. Winkler, H. H., Infect. Immun. 1974, 9, 119.

41. Walker, T. S.; Winkler, H. H., J. Clin. Microbiol. 1979, 9, 645.

42. King, J.; Hamil, T.; Creighton, J.; Wu, S.; Bhat, P.; McDonald, F.; Stevens, T., Microvasc. Res. $2004,67,139$. 


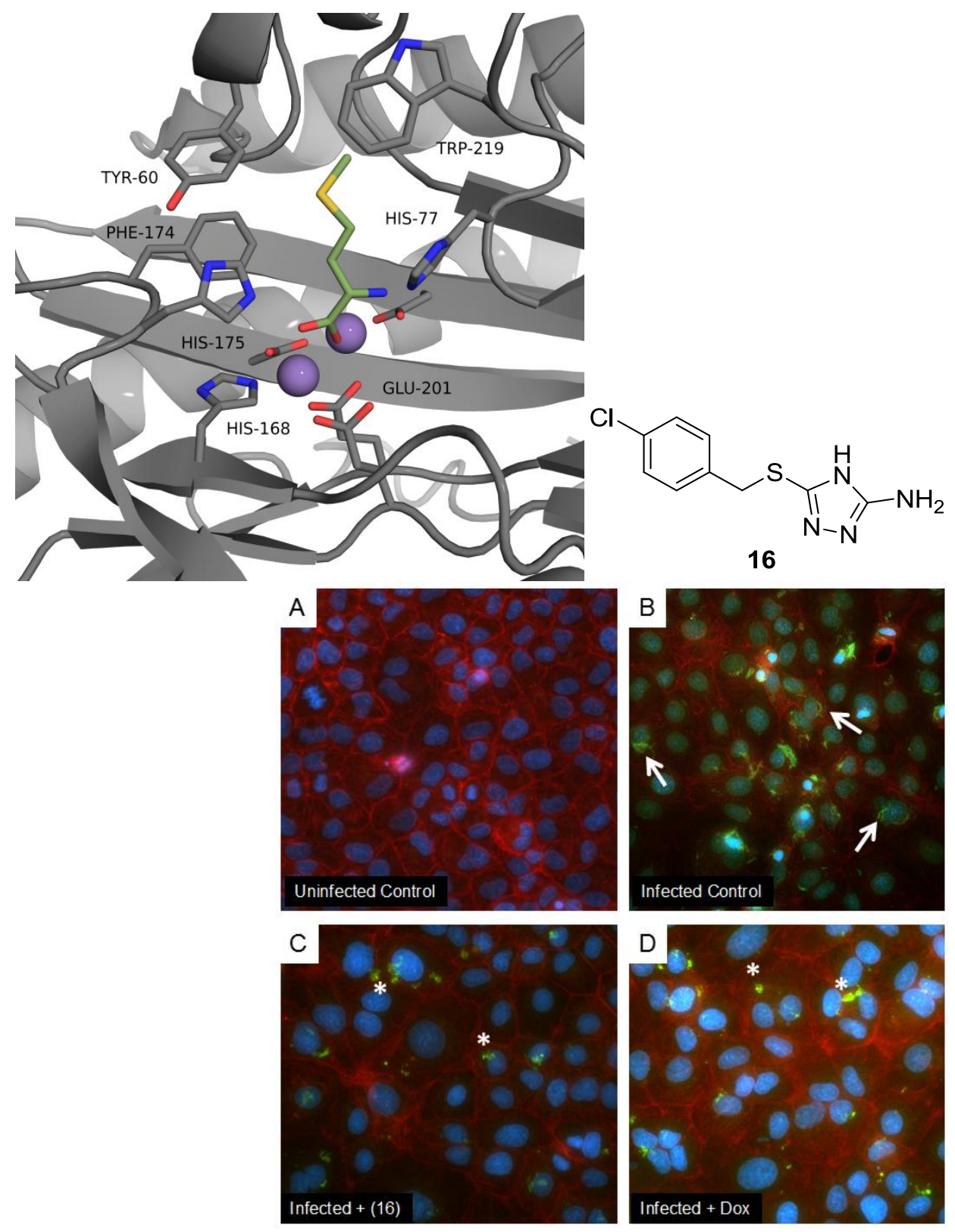

